\title{
Los roedores de Jalisco, México: clave de determinación
}

Edgar G. Godinez ${ }^{1,2^{*}}$ y Sergio Guerrero ${ }^{2}$

Introduction: The state of Jalisco with only $4.0 \%$ of the national area holds about $27.0 \%$ (64 spp) of all rodent species described for Mexico. This knowledge of the richness of rodents from Jalisco is clearly known and refers only to the publications cited the presence of a taxon inside the state border. Therefore, this paper aims to propose an illustrated key to facilitate any interested person a tool that allows them to easily recognize rodent species inhabiting the state of Jalisco. It also represents an effort that seeks to contribute to a better understanding of morphological variation that is so difficult to appreciate in this group of vertebrates. Methods: The key to the identification of rodents of Jalisco was integrated based on the compilation and analysis of bibliographic information, and review of museum specimens deposited in the mammal collection of the Centro de Estudios en Zoología, Universidad de Guadalajara (CZUG). We consider first the original literature where these taxa are described, and ensure the correct identification of the members of the rodents were considered diagnostic characters allowing species easily recognize. With the purpose of facilitating the understanding and accessibility of the key to any interested and not just specialists, have been included illustrations that accompany the text in almost all expressions of character states.

Results: The diversity of rodents of Jalisco consists of 64 species, which fall under 30 genera and five families. As a result they, the rodents are the second most diverse group of mammals in the state, behind only the order Chiroptera (73 spp.). Of all species, 18 (28.0 \%) are monotypic and 46 (72.0\%) polytypic. In relation to the endemic species, six genera and 29 species are endemic to Mexico. The family that had the greatest number of species was Cricetidae ( $40 \mathrm{spp}$ ) that contains about $62.5 \%$ of all rodent species considered for the state. The families Sciuridae and Heteromyidae have eight species each (25.0\%), Geomyidae five (8\%) and Muridae have only three species $(4.5 \%)$. In relation to protected species by the Mexican government, four and one subspecies are subject to special protection, and emphasizes Xenomys nelsoni which is within the category of threatened.

Discussion and conclusions: The state of Jalisco has considerable richness and concentration of endemic species of rodents; this is basically due to its geographical location in the transition zone between the Nearctic and Neotropical region, and a series of topographic and climatic factors. Comparing the total number of species (64) recorded in Jalisco with other regions such as Chiapas (48 spp.) and Oaxaca (56 spp.) suggests that diversity of rodents Jalisco is high. It should be considered an important Jalisco western Mexico area, not only for biodiversity and many endemic species which houses, but also to promote the conservation of its biological richness.

Key words: illustrated key, Jalisco, mammals, Mexico, morphology, rodents.

\section{Resumen}

El estado de Jalisco con solo el $4.0 \%\left(78,588 \mathrm{~km}^{2}\right)$ de la superficie nacional, sostiene cerca del $28.0 \%$ (64 spp) de todas las especies de roedores registradas para México (232 spp). Esta riqueza de roedores es claramente conocida y se remite solo a las

\footnotetext{
'Departamento de Zoología, Instituto de Biología, Universidad Nacional Autónoma de México. Distrito Federal, México E-mail: eggodinez@gmail.com (EGG).

${ }^{2}$ Centro de Estudios en Zoología, Universidad de Guadalajara. Guadalajara, Jalisco, México, CP 44101. E-mail: sergioguerrerovazquez@gmail.com (SG).

"Corresponding author
} 
publicaciones donde citan la presencia de los taxa dentro del límite estatal. Por ende, el presente documento tiene como objetivo proponer una clave ilustrada para facilitar a los especialistas o cualquier interesado, una herramienta que les permita reconocer de manera fiable y precisa las especies de roedores que habitan el estado de Jalisco. Así también, representa un esfuerzo que busca coadyuvar al mejor entendimiento de la variación morfológica que es tan complicado de apreciar en este grupo de vertebrados. La clave para la determinación de los roedores del estado de Jalisco se integró con base en la compilación y análisis de la información bibliográfica, y de la observación puntual de los ejemplares depositados en la colección de mamíferos del Centro de Estudios en Zoología, Universidad de Guadalajara (CZUG). Para esto se consideró en primer término la literatura original de descripción de estos taxa, y en su caso para asegurar la determinación correcta de los integrantes de este grupo, se tomaron en cuenta los caracteres diagnósticos que permiten reconocer fácilmente las especies. Con intención de facilitar la comprensión y accesibilidad de la clave a cualquier interesado y no solo a especialistas, ha sido ilustrada con dibujos originales que acompañan al texto en casi todas las expresiones de los estados del carácter. Un total de 64 especies componen la fauna de roedores del estado de Jalisco, las cuales quedan comprendidas en 30 géneros y cinco familias. Como resultado de ello, los roedores son el segundo grupo de mamíferos más diverso en el estado, solo detrás del orden Chiroptera que está representado por 73 especies. Del total de las especies, 18 (28.0 \%) son monotípicas y $46(72.0 \%)$ politípicas. En relación a los endemismos, seis géneros y 29 especies son endémicos a México. La familia mejor representada fue Cricetidae con 40 especies, que representa cerca del $62.5 \%$ del total de especies de roedores consideradas para el estado, seguida de Heteromyidae y Sciuridae con ocho especias cada una. La familia Goemyidae tiene cinco especies y Muridae solo está conformada por tres especies. En relación a la protección por parte del Gobierno Mexicano, cuatro y una subespecie están sujetas a protección especial, y resalta Xenomys nelsoni que se encuentra dentro de la categoría de amenazada. El estado de Jalisco tiene una riqueza y concentración de especies endémicas de roedores considerable; esto se debe básicamente a su ubicación geográfica en la zona de transición entre la región Neártica y la Neotropical, y por una serie de factores topográficos y climáticos. Comparando el número total de especies (64) registradas en Jalisco con las de otras regiones del país como Chiapas (48 spp) y Oaxaca (56 spp), sugiere que la diversidad de los roedores de esta entidad es alta. Se trata de una zona importante para el occidente de México, no solo para la biodiversidad y el gran número de especies endémicas que resguarda, sino también para promover la conservación de su riqueza biológica.

Palabras clave: clave ilustrada, Jalisco, mamíferos, México, morfología, roedores.

Introducción

Los roedores son mamíferos que se han adaptado con éxito a una amplia diversidad de tipos de ecosistemas, y por ende, han diversificado en una compleja variedad de formas que se distribuyen por todo el planeta, excepto por la Antártida y en algunas islas oceánicas. Con sus 2,277 especies vivientes, el orden Rodentia destaca por ser el grupo más diverso de mamíferos, ya que representa al $42.0 \%$ de la mastofauna a nivel 
mundial (Carleton y Musser 2005). La riqueza de roedores registrada para México es de 232 especies, que corresponde casi a la mitad (49.0\%) del total de mamíferos terrestres del país (Ramírez-Pulido et al. 2005).

La fauna de roedores de Jalisco comenzó a ser estudiada a partir del siglo XIX cuando Dugès (1870) y posteriormente Alston (1879-1882) registran cuatro especies de roedores para Jalisco, particularmente de los alrededores de Guadalajara. Poco después, Allen $(1889,1890)$ enlista como nuevos registros a tres especies y además describe a Sciurus cervicalis para la Sierra Volcán-Nevado de Colima al sur del estado.

Estudios posteriores adicionan 35 taxones a la riqueza de roedores de Jalisco, 26 de ellos descritos por vez primera para la entidad (Merriam 1892, 1895, 1897, 1901a, 1901b, 1902; Thomas 1892, 1893a, 1893b, 1893c; Allen 1897; Nelson 1899; Osgood 1900, 1904; Bailey 1902; Elliot 1903; Goldman 1905). Hacia 1906, Allen realiza el primer estudio centrado en el estado de Jalisco en el que reporta un total de 23 taxa. A partir de esta fecha, las aportaciones al conocimiento de la fauna de roedores del estado disminuyó drásticamente, hubo un periodo de poco más de cuatro décadas en el que se dio a conocer la presencia de solo nueve taxa, pertenecientes a los géneros Peromyscus (Osgood 1909), Neotoma (Goldman 1910), Liomys (Goldman 1911), Reithrodontomys (Howell 1914) y Platygeomys (Goldman 1939). Sin embargo, aunque algunos de estos nombres no se conservan en la actualidad, no fue sino hasta la segunda mitad del siglo pasado cuando la composición taxonómica y nomenclatural de los roedores de Jalisco comenzó a asemejarse a la actual, y fue en este periodo cuando se vio un incremento notable en el número de taxa registrados, a partir de estudios faunísticos detallados (Hooper 1955; Genoways y Jones 1969, 1973; López-Forment et al. 1971), descripciones de nuevos taxa para el estado (Baker 1952, 1954; Hooper 1952; Russell 1953, 1957, 1968; Genoways y Jones 1968, 1969; Genoways 1971) y primeros registros (Hooper 1952; Hall y Kelson 1959; Genoways y Jones 1971).

Durante el comienzo de los 90's existió un interés por conocer la fauna de mamíferos de Jalisco, apareciendo un par de trabajos que intentaron resumir el conocimiento hasta entonces acumulado sobre la riqueza mastozoológica de la entidad (Iñiguez y Santana 1993; Guerrero et al. 1995). Ambos estudios reconocen 63 especies de roedores con distribución en el estado. Casi una década después, Guerrero y Cervantes (2003) reunieron la información de las colecciones de mamíferos tanto nacionales como extranjeras en el que enlistan 63 especies de roedores. Por su parte, Iñiguez y Santana (2005) mencionan que en la entidad el orden Rodentia está compuesto por 61 especies. Sin embargo, recientemente con base en la información bibliográfica, se reconocio que la fauna de roedores nativa del estado de Jalisco está representada por 60 especies (Godinez et al. 2011).

En la actualidad, la adición en el número de taxa registrados para Jalisco está relacionada con la reciente descripción de especies nuevas, la revalidación de varias de ellas en los últimos años y la ampliación del área de distribución conocida para distintas especies.

Así por ejemplo, Mathis et al. (2013) mencionan que Thomomys atrovarius es un habitante de la región de Bolaños, al norte del estado.

Otras contribuciones aportan los primeros datos sobre biología de poblaciones de ciertas especies de roedores (Mandujano 1997; Vázquez et al. 2000; Zalapa et al. 2005), 
información sobre el uso y relación con el hábitat (Roberts etal. 1997; Vázquez-Domínguez et al. 2002; Domínguez-Castellanos et al. 2007), algunos trabajos relacionados con morfología (Sánchez-Cordero y Villa-Ramírez 1988; Morales y Engstrom 1989), los que determinan el estado taxonómico de algunos taxa (Demastes et al. 2003; Hafner et al. 2004; Carleton y Arroyo-Cabrales 2009; Hanson et al. 2010; Fernández et al. 2012), y guías de campo en las que incluyen algunas de las especies (Ceballos y Miranda 1986, 2000).

El estado de Jalisco con solo el $4.0 \%\left(78,588 \mathrm{~km}^{2}\right)$ de la superficie nacional, sostiene cerca del $28.0 \%$ (64 spp) de todas las especies de roedores localizadas en México, las cuales están conformadas en 30 géneros y cinco familias. Con ello se puede establecer que el estado es una de las entidades más ricas en este grupo de vertebrados en el país (Ceballos y Oliva 2005), incluso que los estados de Chiapas (48 spp; Retana y Lorenzo 2002) y Oaxaca (56 spp; Briones-Salas y Sánchez-Cordero 2004).

Debido a todo lo antes señalado, en el que se resalta que la diversidad de los roedores del estado de Jalisco es claramente conocida, por ende, el presente documento tiene como objetivo proponer una clave taxonómica ilustrada para facilitar a los especialistas o cualquier interesado, una herramienta que les permita reconocer de manera fiable y precisa las especies de roedores que habitan el estado de Jalisco, con base principalmente en la combinación de caracteres tanto morfológicos somáticos como craneales. Así también, representa un esfuerzo que busca coadyuvar al mejor entendimiento de la variación morfológica que es tan complicado de apreciar en este grupo de vertebrados.

La clave ilustrada para la determinación de los roedores del estado de Jalisco se integró con base en la compilación y análisis de la información bibliográfica, para lo cual se consideró, en primer término, la literatura original de descripción de estos taxa. Para facilitar y en su caso asegurar la determinación correcta de los integrantes de este grupo, se tomaron en cuenta los caracteres diagnósticos que permiten reconocer fácilmente a las especies, enfatizando aquéllos estados del carácter que reflejan las poblaciones de las especies que habitan la entidad. Por tanto, los atributos de los roedores considerados en el presente trabajo se derivaron a partir de los datos de las revisiones taxonómicas de las familias Geomyidae (Merriam 1895), Sciuridae (Nelson 1899; Howell 1938), de los trabajos de algunos miembros de los géneros Perognathus (Osgood 1900), Oryzomys (Merriam 1901a; Goldman 1918; Carleton y Arroyo-Cabrales 2009), Peromyscus (Osgood 1909), Neotoma (Goldman 1910; Hall y Genoways 1970), Reithrodontomys (Howell 1914; Hooper 1952), Orthogeomys (Nelson y Goldman 1930), Thomomys (Nelson y Goldman 1934), Nelsonia (Hooper 1954), Baiomys (Packard 1960), Pappogeomys (Russell 1968), Spermophilus (Helgen et al. 2009), de la especie Sciurus aureogaster (Musser 1968), notas sobre faunas locales (Allen 1906; Hooper 1955; Musser 1969; Genoways y Jones 1969, 1973), estudios faunísticos regionales (Carleton 1977), monografías (Hall 1981; Villa-Ramírez y Cervantes 2003), y de guías de campo (Ceballos y Miranda 1986, 2000).

Para elegir los caracteres que conforman las opciones de la clave, se hizo énfasis en la similitud entre taxa, la superposición y apariencia constante de las características que definen las especies; debido a ello, una combinación de un conjunto de caracteres 
tanto morfológicos externos como del cráneo se consideran en cada alternativa. Con esto se pretende minimizar los errores cometidos en las determinaciones y conducir al reconocimiento de los integrantes de los roedores de manera fiable y precisa. Se procura también eliminar las dudas que puedan surgir debido a la aparición de caracteres variables, difíciles de definir, y/o de aquéllos con margen de interposición. Debido a lo señalado anteriormente y a lo relativo de algunos de los atributos de los roedores utilizados en este trabajo, los estados del carácter que conducen a determinar correctamente al taxón que se está tratando deben considerarse en conjunto y no individualmente.

Se incluye la distribución geográfica y/o parte del hábitat de cada especie al final de cada alternativa, no como sustituto de un carácter morfológico, sino para reforzar la alternativa que el lector tiene que tomar.

Algunos de los caracteres incluidos se derivaron de otras claves ya existentes (Osgood 1900, 1909; Bailey 1902; Goldman 1910, 1911, 1918; Hooper 1952; Russell 1968; Baker 1969; Anderson 1972; Hall 1981; Jones y Manning 1992; Williams et al. 1993; Frey 2007; Mathis et al. 2013) y de la observación directa de los ejemplares en cuestión.

Para evaluar los caracteres considerados en cada alternativa de la clave se partió de la información bibliográfica y de la observación puntual de los ejemplares depositados en la colección de mamíferos del Centro de Estudios en Zoología, Universidad de Guadalajara (CZUG).

Con intención de facilitar la comprensión y accesibilidad de la clave a cualquier interesado y no solo a especialistas, se ilustró con dibujos que acompañan al texto en casi todas las expresiones de los estados del carácter. Las ilustraciones son dibujos originales realizados a partir de los ejemplares de colección y en caso de no haber contado con estos se elaboraron a partir de fotografías o de las publicaciones (Osgood 1909; Goldman 1910, 1918; Hooper 1952; Russell 1968; Baker 1969; Anderson 1972; Jones y Manning 1992; Frey 2007).

El formato de la clave es dicotómico y se ha perfilado para ser considerada hasta nivel de especie, siguiendo las recomendaciones de Metcalf (1954) y Mayr (1969) para clave yuxtapuesta. La disposición de las familias de roedores (subclaves), es según al orden filogenético presentado en Godinez et al. (2011). La clave se desarrolló primeramente con el objeto de auxiliar en la determinación de los ejemplares adultos y recolectados para ser ingresados a una colección biológica. Sin embargo, este estudio puede ser una herramienta de gran utilidad para trabajar con individuos vivos en campo, ejemplares de museo o en su caso cuando solo se dispone del cráneo. Es preciso resaltar, que al considerar estas alternativas, el lector debe tener la experiencia necesaria para reconocer los caracteres que definen las especies, y con ello considerar solo los atributos de las alternativas que son requeridos. Para esto, se ordenaron los caracteres morfológicos externos siempre al comienzo de cada enunciado, seguida por los del cráneo y se refuerza al final con la distribución o hábitat de la especie en cuestión. Aunado a lo mencionado anteriormente, se atribuye que los caracteres de los roedores empleados en este trabajo son totalmente excluyentes y el número relevante de ilustraciones pueden servir como una excelente referencia.

Las medidas somáticas consideradas en las opciones de las claves se registraron de acuerdo a la propuesta de Hall (1981), y se ilustran en la Figura 1. Las medidas de 20 variables craneales que se especifican en la clave se muestran en la Figura 2 (Hooper 1952; Hall 1981; Patton et al. 2008). 
Las especies nativas incluidas así como la nomenclatura taxonómica utilizada en este documento está de acuerdo al criterio de Godinez et al. (2011). Adicionalmente, se adoptó la propuesta de Hafner et al. (2007) quienes asignaron el nombre de Liomys como sinonimia de Heteromys. Se le asignó el estatus de especie valida al taxón Dipodomys phillipsi ornatus siguiendo la recomendación de Fernández et al. (2012), y en lo que respecta a la clasificación y distribución del género Thomomys se siguió a ÁlvarezCastañeda (2010) y Mathis et al. (2013). Los tres taxa exóticos miembros de la familia Muridae se integran a este trabajo.

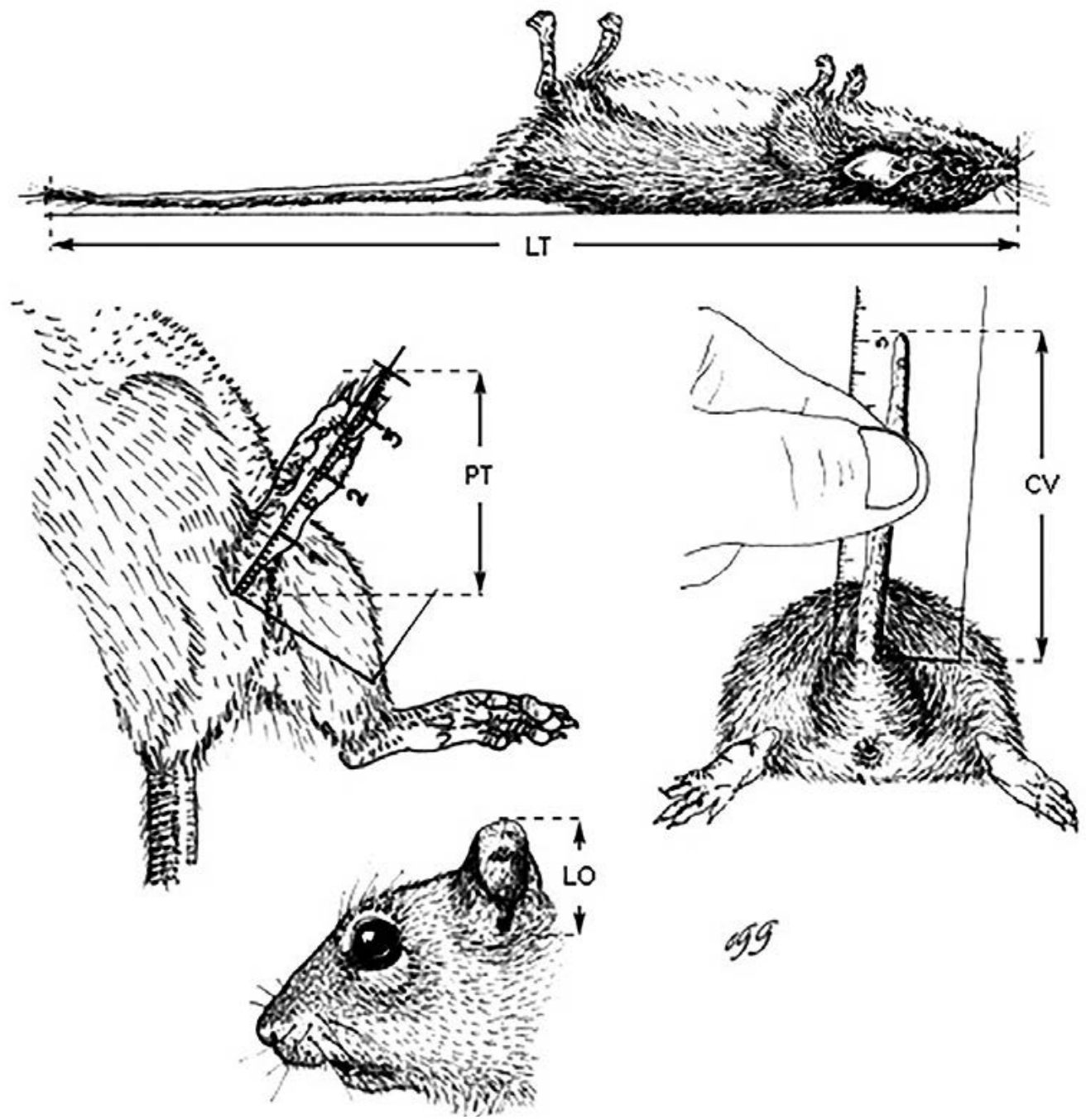

Figura 1. Medidas somáticas estándar para mamíferos: longitud total (LT), longitud de la cola vertebral (CV), longitud de la pata trasera (PT) y longitud de la oreja (LO).

\section{Claves para la determinación de los roedores de Jalisco}

Clave para las familias de roedores

1. Presencia de abazones externos (Fig. 3a); molares bilofodontos, en una disposición bicolumnar o monocolumnar (Fig. 4a, b). .2

$1^{\prime}$. Ausencia de abazones externos (Fig. 3b); molares con cúspides evidentes o lofos alternos sobre el eje longitudinal del diente (Fig. 4c, d).... 
Figura 2. Medidas craneales para roedores consideradas en la clave: longitud occipitonasal (LON), longitud condilobasal (LCB), longitud basal (LB), longitud basilar (LBR), longitud del rostro (LR), ancho del rostro (AR), longitud nasal (LN), anchura zigomática (AZ), anchura de la caja craneana (ACC), constricción interorbital $(\mathrm{Cl})$, longitud palatal (LPA), longitud del foramen incisivo (LFI), longitud de la bula auditiva (LBA), anchura de la bula auditiva (ABA), longitud interparietal (LIP), anchura interparietal (AIP), longitud de la hilera molar de dientes (LHMD), anchura de la fosa mesopterigoidea (AFM), anchura de la placa zigomática (APZ) y profundidad del cráneo (PC).
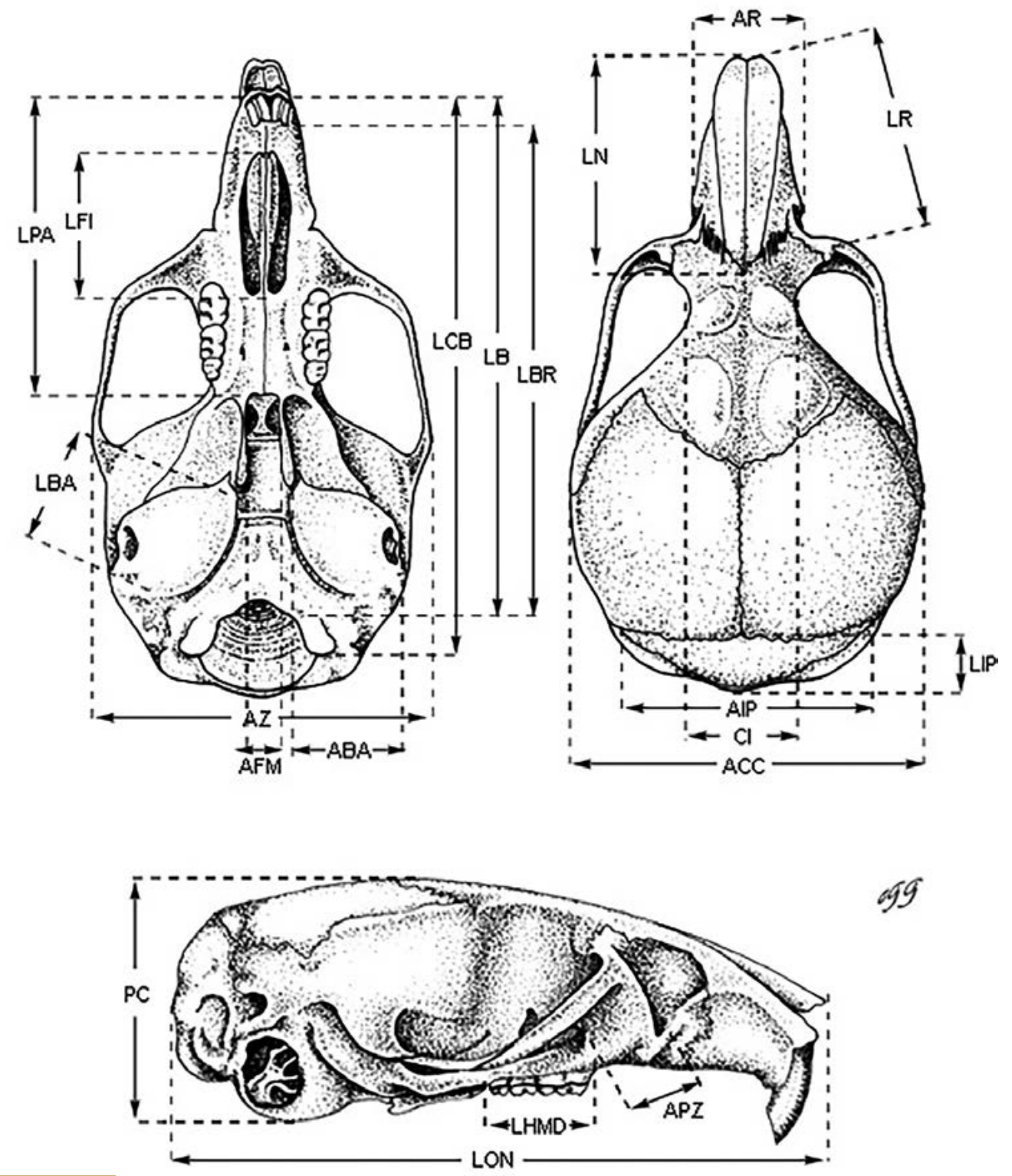

699

2. Cuerpo alargado con forma de torpedo (Fig. 5; debido a su adaptación fosorial); extremidades reducidas, con los miembros anteriores provistos de garras es proporcionalmente grandes; pabellones auriculares (pina) rudimentarios; la región interorbital está constreñida, su anchura siempre es menor que la del rostro; foramen infraorbital pequeño y desplazado posteriormente hasta la placa zigomática (Fig. 6a); primer premolar superior con forma de reloj de arena (Fig. 7) Geomyidae

2' Cuerpo no en forma de torpedo; las extremidades no están reducidas, los miembros anteriores tienen garras relativamente pequeñas; pabellones auriculares (pina) notoriamente desarrollados; la región interorbital es amplía, su anchura siempre es mayor que la del rostro; el foramen infraorbital es relativamente grande y más bien se encuentra desplazado anteriormente, el cual surge como un gran conducto que se extiende transversalmente por el rostro (Fig. 6b); el primer premolar superior no está constreñido por el centro (Fig. 7b).........Heteromyidae 
3. Cola con pelo abundante, por lo común largo y laxo (Fig. 8a); más de tres dientes molariformes, superiores y/o inferiores; proceso postorbital presente y prominente (Fig. 9a) Sciuridae

3'. Colacon peloescaso, relativamentecortoy ralo(Fig. 8b); solotresdientesmolariformes, superioresy/oinferiores; procesopostorbitalausente(Fig. 9b)... 4

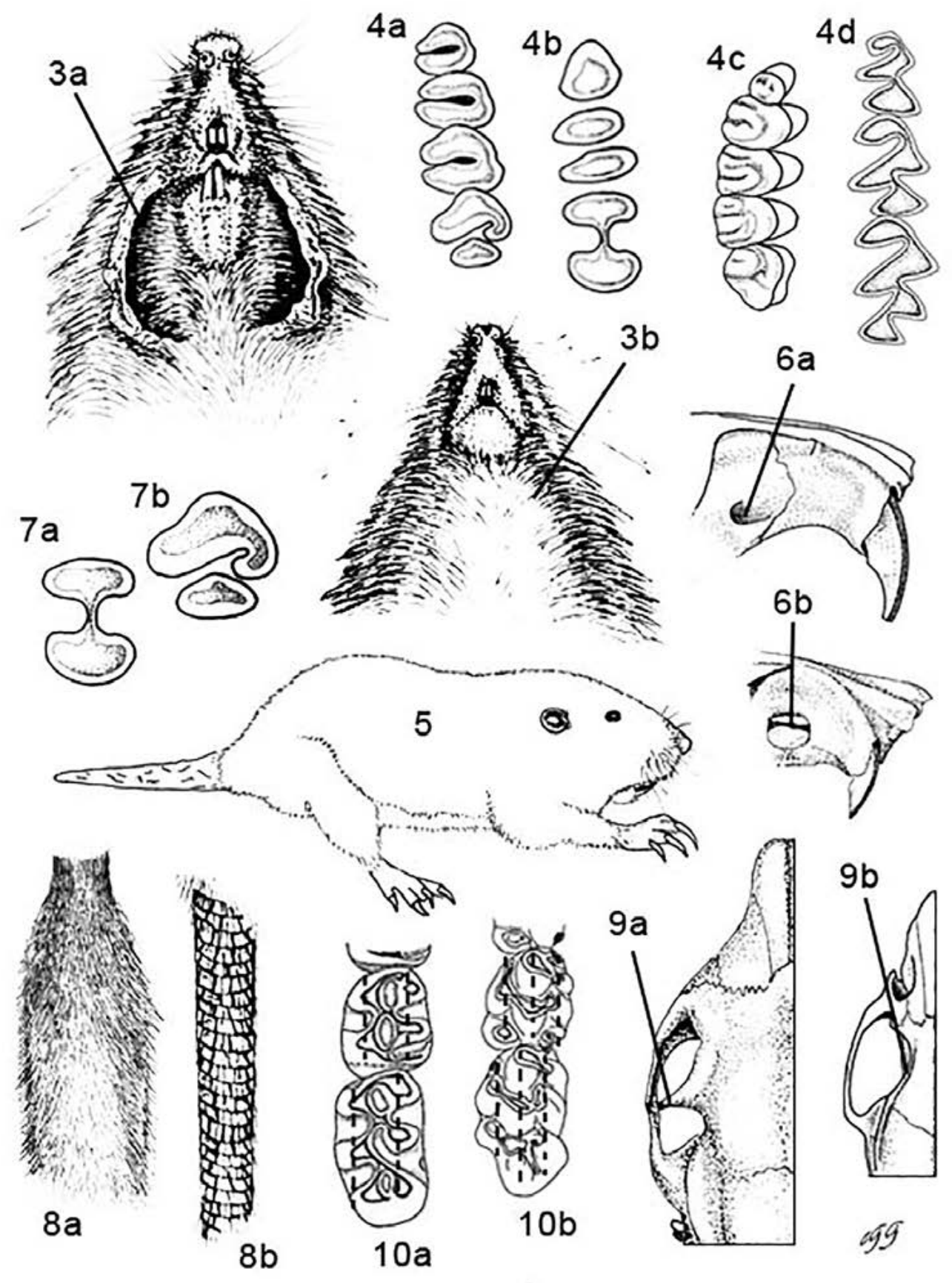

4. En general la coloración de estos individuos es marcadamente bicolor, principalmente el color del vientre por lo común contrasta notoriamente con 
la del dorso del cuerpo; la cola al menos está parcialmente desnuda y no es conspicuamente escamosa; principalmente en los dos primeros molares hay dos hileras de cúspides arregladas longitudinalmente o, pueden ser molares de corona plana con lofos y pliegues de esmalte dispuestos alternamente (Fig. 10a)...

Cricetidae

4 '. En general la condición bicolor del cuerpo de estos individuos no es tan marcada, principalmente el color del vientre no contrasta claramente con la del dorso del cuerpo; la cola está desnuda y es conspicuamente escamosa; principalmente en los dos primeros molares hay más bien tres hileras de cúspides arregladas longitudinalmente (Fig. 10b) Muridae

\section{Clave para los géneros y especies de la familia Sciuridae}

1. El dorso y lados del rostro presentan rayas distintivas claras y oscuras en disposición longitudinal (Fig. 11); canal infraorbital ausente, el cual es remplazado por el foramen infraorbital que forma un pequeño agujero redondeado que pasa a través de la placa zigomática. Se distribuyen en una solo localidad al norte del estado, al noreste de Huejuquilla el Alto..........................................Neotamias bulleri

$1^{\prime}$. El dorso y lados del rostro no presentan rayas claras y oscuras; canal infraorbital presente, generalmente es como una pequeña hendidura que pasa entre el rostro y la placa zigomática. Se distribuyen en todo el estado.

2. Cola densamente peluda y larga $(225-310 \mathrm{~mm})$, mayor del $90 \%$ de la longitud de la cabeza y el cuerpo; pelaje del cuerpo relativamente largo, fino y denso; orejas comparativamente largas, siempre sobrepasan notoriamente la corona de la cabeza; las extremidades posteriores son mucho más largas que las anteriores; visto dorsalmente el cráneo no tiene forma triangular, debido que el arco zigomático está casi completamente paralelo al eje longitudinal del cráneo (Fig. 12a); el arco zigomático es más alto que ancho puesto que no se inclina lateralmente (Fig. 13a); escotadura de la placa zigomática al mismo nivel del segundo premolar superior (Fig. 14a); primer premolar superior ausente o vestigial (Fig. 14c).... Sciurus 3

$2^{\prime}$. Cola de escasa a moderadamente peluda y comparativamente corta $(60-270 \mathrm{~mm})$, generalmente menor del $95 \%$ de la longitud de la cabeza y el cuerpo; pelaje del cuerpo relativamente corto, áspero y ralo; orejas cortas que usualmente no sobrepasan de forma apreciable la corona de la cabeza (excepto en Otospermophilus variegatus); las extremidades posteriores no son más largas que las anteriores; visto dorsalmente el cráneo tiene forma triangular, debido que el arco zigomático converge anteriormente (Fig. 12b); el arco zigomático es más ancho que alto puesto que se inclina lateralmente (Fig. 13b); escotadura de la placa zigomática más bien se encuentra al mismo nivel del primer molar superior (Fig. 14b); primer premolar superior notoriamente desarrollado (Fig. 14d)........5

3. El cuerpo es robusto; el pelo de estos individuos es relativamente largo, denso y laxo; coloración general del cuerpo gris oscuro, impregnado ligeramente de 
blanco y amarillo herrumbruso; el amplio anillo ocular y el hocico (blanquecinos) contrastan notoriamente; cola ampliamente bordeada de blanco; el primer premolar superior está ausente. Su distribución está restringida a la parte templada que se localiza por arriba de los 1,400 m de altitud, principalmente desde el norte del estado hacia el sur (a través del centro) hasta la Sierra VolcánNevado de Colima, y con poblaciones al norte de la Sierra Madre del Sur Sciurus nayaritensis

3'. El cuerpo es esbelto; el pelo de estos individuos por lo general es relativamente corto, ralo y tosco; coloración general del cuerpo grisáceo, en ocasiones puede estar impregnado intensamente de negro y amarillento; el angosto anillo ocular y hocico (usualmente de color ante o amarillento) no contrastan claramente; cola angostamente bordeada de blanco; el primer premolar superior es vestigial. En Jalisco se distribuyen en casi todo el territorio (con excepción de Los Altos) y habitan ambientes muy diversos, desde el nivel del mar hasta los 3,400 m de altitud.

4. Especie de color grisáceo, teñido marcadamente de negro y amarillento principalmente sobre la línea media dorsal y la cadera; las orejas y el anillo ocular son amarillentos. Su distribución se extiende a través de la planicie costera y las montañas aledañas................................................Sciurus colliaei

4 '. Especie de color grisáceo, con el dorso del cuerpo interrumpido por dos parches (de intensidad variada) de color ante anaranjado o rojizo, uno sobre la nuca y el otro situado en la cadera y base de la cola; orejas de color ante-grisáceo y el anillo ocular puede ser de color ante o blanquecino. Se distribuyen desde el norte, extendiéndose hacia el sur (a través del centro) hasta los límites con los estados de Colima y Michoacán Sciurus aureogaster

5. Parte dorsal del cuerpo moteado (Fig. 15a); orejas cortas y redondeadas, las cuales nunca sobrepasan el nivel de la corona de la cabeza (Fig. 15b); tienen la base de la cola cilíndrica; el largo de la cola $(60-170 \mathrm{~mm})$ es menor del $70 \%$ de la longitud de la cabeza y el cuerpo; cresta del parastilo cambiando fuertemente de dirección al unirse con el protocono en los dos primeros molares superiores.

6

5'. Parte dorsal del cuerpo sin motas; orejas largas que sobrepasan moderada o notoriamente por arriba de la corona de la cabeza (Fig. 15c); no tienen la base de la cola cilíndrica, sino más bien la constitución del pelo se encuentra a todo lo largo homogéneamente distribuido; el largo de la cola (120-270 mm) es mayor del $70 \%$ de la longitud de la cabeza y el cuerpo; cresta del parastilo sin un cambio abrupto de dirección al unirse con el protocono en los dos primeros molares superiores

6. Especie de talla grande, su longitud total es mayor de $260 \mathrm{~mm}$; longitud de la pata trasera mayor de $45 \mathrm{~mm}$; dorso con una serie de manchas (de forma rectangular) claras bien definidas y arregladas en 9 a 13 hileras longitudinales; el extremo distal de la cola nunca es de color negro; cráneo de estructura fuerte y maciza; 
el proceso hamular es visible cuando se ve lateralmente, debido a las bulas auditivas que están ligeramente dilatadas (Fig. 16a). En Jalisco esta especie se distribuye en los valles desde el centro-sur del estado, extendiéndose hasta Los Altos y extremo noreste de la entidad. .Ictidomys mexicanus

6'. Especie de talla pequeña, su largo total es menor de $260 \mathrm{~mm}$; longitud de la pata trasera menor de $45 \mathrm{~mm}$; dorso con una serie de manchas (de forma circular) claras no bien definidas e irregularmente distribuidas, las que se pierden hacia la parte anterior del cuerpo; el extremo distal de la cola generalmente es de color negro; cráneo de estructura delicada; el proceso hamular no es visible cuando se ve lateralmente, debido a las bulas auditivas que están fuertemente dilatadas (Fig. 16b). En Jalisco esta especie se restringe en la parte semidesértica que se localiza en la región Altos Norte al extremo este-noreste del estado. Xerospermophilus spilosoma

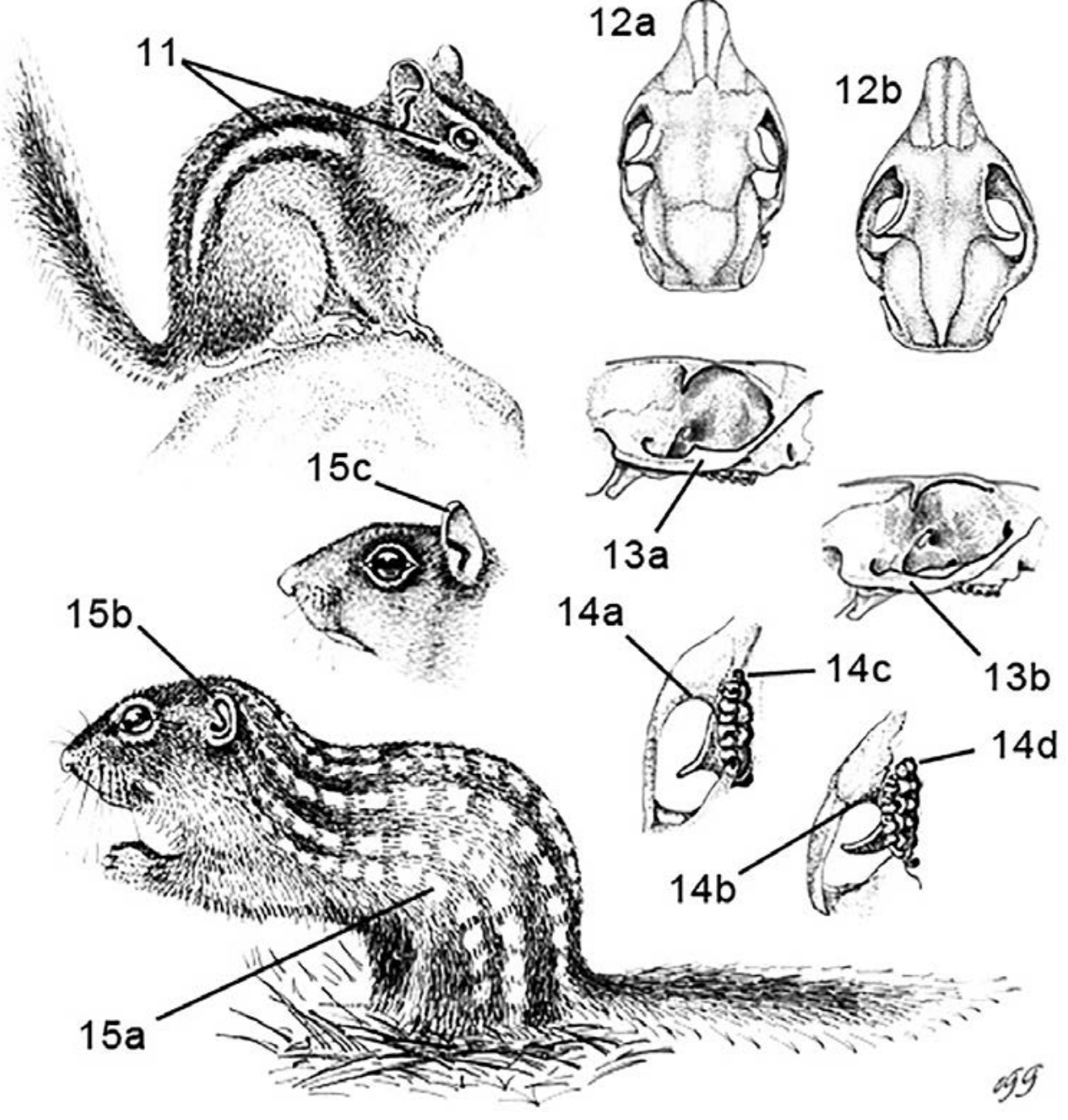

7. Pelaje de la parte superior del cuerpo jaspeado de negro y blanco; orejas muy largas y puntiagudas, las cuales sobrepasan notoriamente la corona de la 
cabeza; foramen supraorbital abierto (Fig. 17a); foramen incisivo relativamente largo (Fig. 18a); los parietales presentan un par de tenues protuberancias que se encuentran cerca del extremo posterior del cráneo que al unirse forman una pequeña cresta (Fig. 19a); el primer premolar superior está bien desarrollado (Fig. 20a). Su distribución se extiende a casi todo el territorio (excepto por la vertiente del Pacífico) y se localizan en una gran variedad de condiciones ambientales Otospermophilus variegatus

7'. Pelaje de la parte superior del cuerpo de aspecto canoso (una mezcla de negruzco y canela); orejas cortas y más o menos redondeadas, las cuales no sobrepasan apreciablemente la corona de la cabeza; foramen supraorbital cerrado (Fig. 17b); foramen incisivo relativamente corto (Fig. 18b); parietales con un par de tenues protuberancias que convergen cerca del extremo posterior del cráneo pero sin formar una cresta (Fig. 19b); el primer premolar superior es diminuto (Fig. 20b). Su distribución se restringe principalmente en la parte tropical que se localiza al oeste-suroeste y extremo sureste de la entidad Notocitellus 8

8. Ardilla de cuerpo fornido y de gran tamaño, su longitud total es mayor de 380 mm; la cola está bandeada con alrededor de 15 anillos negruzcos (Fig. 21a); mejillas de color pardo anaranjado; anchura interorbital mayor de $13.5 \mathrm{~mm}$. Estos individuos son abundantes al sur (ladera oeste de la Sierra Volcán-Nevado de Colima) y oeste-suroeste del estado, principalmente a lo largo de la costa sur y en sus inmediaciones................................................ Notocitellus annulatus

8'. Ardilla de cuerpo esbelto y de tamaño relativamente pequeño, su longitud total es menor de 380 mm; la cola no está bandeada (Fig. 21b); mejillas de color ante; anchura interorbital menor de $13.5 \mathrm{~mm}$. Estos individuos se conocen de una sola localidad al extremo sureste del estado en el municipio de Jilotlán de los Dolores Notocitellus adocetus

Clave para los géneros y especies de la familia Heteromyidae

1. Cuerpo con forma bípeda (debido a su locomoción saltatorial), miembros posteriores desproporcionadamente más grandes que los anteriores (Fig. 22a); planta de la pata trasera cubierta densamente de pelo; muslo con una franja blanca que se extiende desde la parte anterior hasta la base de la cola (Fig. 22c); base anterior del arco zigomático agrandada (Fig. 23a); bulas auditivas excesivamente dilatadas (Fig. 24a). Dipodomys 2

1'. Cuerpo con forma cuadrúpeda (debido a su locomoción cursorial), miembros posteriores no más grandes que los anteriores (Fig. 22b); planta de la pata trasera desnuda o parcialmente cubierta escasamente de pelo; muslo sin franja blanca (Fig. 22d); la base anterior del arco zigomático no está agrandada (Fig. 23b); las bulas auditivas en ocasiones pueden estar algo dilatadas (Fig. 24b)....

2. Especie con cinco dedos en la pata trasera, el primer digito (pulgar) es vestigial (Fig. 25a); la cola es relativamente corta (generalmente $<155 \mathrm{~mm}$ ), por lo común es menor del $150 \%$ de la longitud de la cabeza y el cuerpo; la superficie dorsal y ventral incluyendo la cresta de pelos largos de la porción distal de 
la cola, son de color pardo oscuro (Fig. 26a); bulas mastoideas relativamente dilatadas, su anchura generalmente es mayor de 23.8 mm (Fig. 27a); el interparietal es más o menos alargado antero-posteriormente (Fig. 27c). Su distribución se restringe en la región Altos Norte al extremo este-noreste de la entidad.

Dipodomys ordii

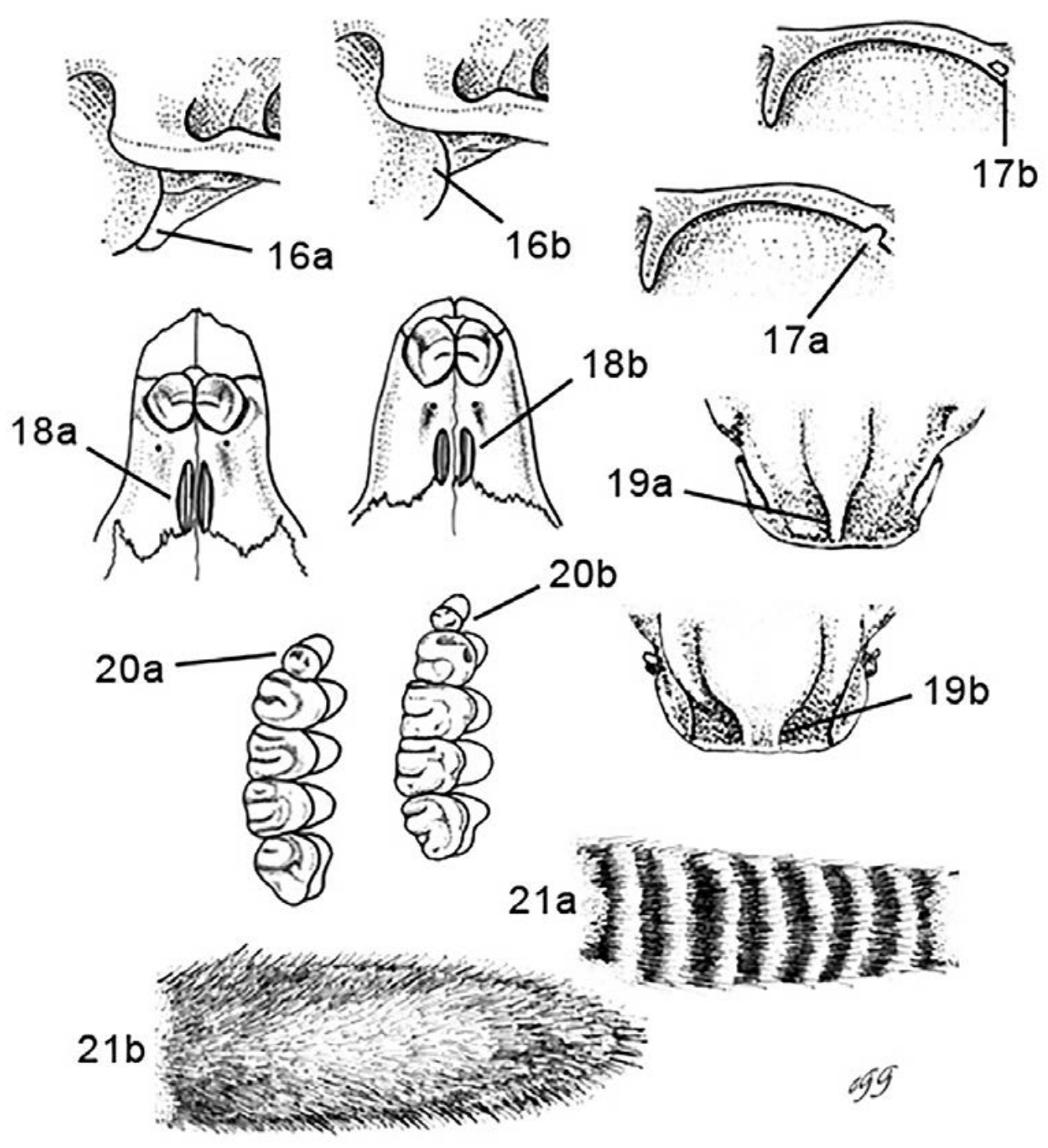

$2^{\prime}$. Especie con cuatro dedos en la pata trasera, el primer digito (pulgar) está ausente (Fig. 25b); la cola es relativamente larga (generalmente $>155 \mathrm{~mm}$ ), por lo común es mayor del $150 \%$ de la longitud de la cabeza y el cuerpo; la superficie dorsal y ventral incluyendo la cresta de pelos largos de la porción distal de la cola, son de color negro, excepto por la parte apical que puede ser blanca (Fig. 26b); bulas mastoideas medianamente dilatadas, su anchura generalmente es menor de 23.8 mm (Fig. 27b); el interparietal es más o menos ovalado (Fig. 27d). Se distribuyen al extremo este-noreste y norte del estado.

Dipodomys ornatus 
3. Superficie anterior de los incisivos superiores con un surco longitudinal (Fig. 28a); el pelaje de los individuos varía de sedoso a una mezcla escasa o moderada de pelos ásperos y finos, y en ocasiones presentan pelos rígidos como espinas sobre el dorso y costados del cuerpo; bulas auditivas dilatadas; las bulas mastoideas están infladas y forman parte de la superficie dorsal del cráneo 4
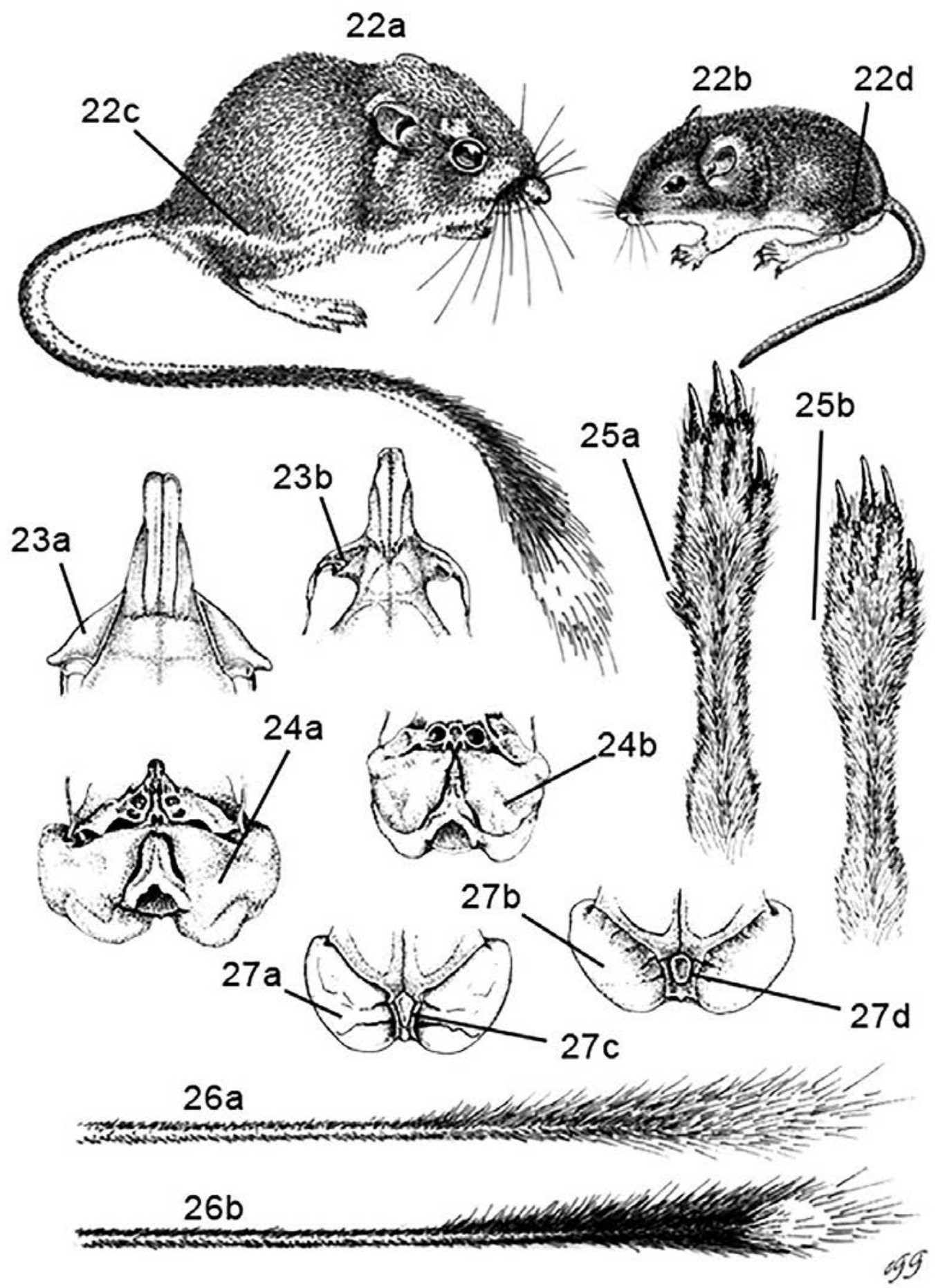

3'. Superficie anterior de los incisivos superiores lisa, sin surco longitudinal (Fig. 28b); el pelaje de los individuos es áspero con abundantes pelos rígidos como 
espinas sobre el dorso y los costados del cuerpo; bulas auditivas no dilatadas (Fig. 29); las bulas mastoideas no están infladas y nunca forman parte de la superficie dorsal del cráneo (Fig. 30). Heteromys 6

4. Son individuos de talla pequeña $(<130 \mathrm{~mm})$ y de pelaje suave y sedoso; una mancha clara postauricular está presente; la cola siempre es más corta que la cabeza y el cuerpo, por lo general su longitud es menor de $55 \mathrm{~mm}$; bulas mastoideas notoriamente dilatadas, se sobreponen notoriamente sobre la superficie dorsal del cráneo para formar parte considerable de este (Fig. 31a), y se prolongan posteriormente más allá del plano del occipital (Fig. 31c); el interparietal está fuertemente constreñido (Fig. 31e), su anchura es menor que la constricción interorbital. Su distribución comprende los valles del centro-sur del estado, extendiéndose hasta Los Altos y parte del norte de la entidad Perognathus flavus

4. Son individuos de talla mediana $(>130 \mathrm{~mm}$ ) y de pelaje comparativamente áspero y cerdoso; nunca presentan una mancha clara postauricular; la cola es igual o mucho más larga que la cabeza y el cuerpo, por lo común su longitud es mayor de $55 \mathrm{~mm}$; bulas mastoideas ligeramente dilatadas, solo se sobreponen levemente sobre la superficie dorsal del cráneo (Fig. 31b) y nunca se prolongan posteriormente más allá del plano del occipital (Fig. 31d); el interparietal no está constreñido, su anchura es mayor que la constricción interorbital (Fig. 31f). Su distribución cubre exclusivamente la región semidesértica de Jalisco, que se localiza en la región Altos Norteyextremonorestedelestado. Chaetodipus 5

5. Pelaje con cerdas numerosas y fácilmente visibles y distribuidas principalmente en torno a la cadera (Fig. 32a); individuos de talla relativamente pequeña y cuerpo esbelto, longitud de cabeza y cuerpo menor de $90 \mathrm{~mm}$; la cola es larga, es mayor del $110 \%$ de la longitud de la cabeza y el cuerpo; cresta de pelos largos sobre la porción terminal de la cola presente y conspicua (Fig. 32c); a menudo presentan aunque bien definida línea lateral estrecha de color ante; anchura interorbital menor de $6.8 \mathrm{~mm}$. Se distribuyen al extremo este-noreste y parte este del norte del estado Chaetodipus nelsoni

5. Pelaje sin cerdas largas o espinas duras en ninguna parte del cuerpo (Fig. 32b); individuos de tamaño grande y cuerpo fornido, longitud de cabeza y cuerpo mayor de $90 \mathrm{~mm}$; la cola es comparativamente corta, es menor del $110 \%$ de la longitud de la cabeza y el cuerpo; cresta de pelos largos sobre la parte apical de la cola ausente (Fig. 32d); presentan una línea lateral más bien amplia y de color ocre; anchura interorbital mayor de $6.8 \mathrm{~mm}$. La distribución de estos individuos está restringida en la región Altos Norte. .Chaetodipus hispidus

6. Extremidades posteriores con 5 tubérculos plantares (Fig. 33a); coloración general del cuerpo pardo grisáceo; línea lateral generalmente presente de color rosa pálido o ante; la cola está cubierta dorsalmente con abundantes pelos largos, de modo que la cola no adquiere una apariencia escamosa (Fig. 34a); los procesos del pterigoideo son anchos (Fig. 35a). En la entidad esta especie se distribuye 
preferentemente en áreas templadas y semiáridas. Heteromys irroratus

6'. Extremidades posteriores con 6 tubérculos plantares (Fig. 33b); coloración general del cuerpo pardo rojizo; línea lateral siempre presente de color pardo anaranjado u ocráceo; la cola está cubierta dorsalmente con escasos pelos cortos, de manera que la cola obtiene una apariencia escamosa (Fig. 34b); los procesos del pterigoideo son angostos (Fig. 35b). En el estado se distribuyen principalmente en zonas tropicales

7. Individuos de gran tamaño, longitud de la pata trasera mayor de $30 \mathrm{~mm}$; línea media lateral de color ocre pálido; longitud occipitonasal de 33.0 a 33.5 mm; anchura zigomática mayor de $15 \mathrm{~mm}$. Se distribuyen desde el sur de Mazamitla hasta Pihuamo al sureste del estado. Heteromys spectabilis

7 . Individuos de talla mediana a relativamente pequeña, longitud de la pata trasera menor de $30 \mathrm{~mm}$; línea media lateral de color pardo anaranjado; longitud occipitonasal de 28.9 a $32.0 \mathrm{~mm}$; anchura zigomática menor de $15 \mathrm{~mm}$. Se distribuyen desde el centro-este, extendiéndose hacia el occidente y sur-sureste de la entidad, encontrando su límite en el Pacifico y en los estados de Nayarit, Colima y Michoacán. Heteromys pictus

Clave para los géneros y especies de la familia Geomyidae

1. Con un surco longitudinal sobre la superficie anterior de los incisivos superiores (Fig. 36a); miembros anteriores provistos de patas grandes y garras relativamente largas y robustas (Fig. 36c); la fosa basitemporal está presente (Fig. 37a)............2

1 '. Sin un surco longitudinal sobre la superficie anterior de los incisivos superiores (Fig. 36b); miembros anteriores provistos de patas pequeñas y garras comparativamente cortas y esbeltas (Fig. 36d); la fosa basitemporal está ausente (Fig. 37b). Thomomys 4

2. Pelaje áspero, por lo común ralo y cerdoso; pata trasera mayor de $52 \mathrm{~mm}$; cráneo con el rostro relativamente largo y amplio (Fig. 38a); la región interorbital no está constreñida (Fig. 38c), su anchura generalmente es mayor de 11.5 mm. En Jalisco se conocen de una sola localidad al extremo sureste del estado en el municipio de Jilotlán de los Dolores Orthogeomys grandis

$2^{\prime}$. Pelaje más bien suave, por lo común denso y laxo; pata trasera menor de $52 \mathrm{~mm}$; cráneo con el rostro relativamente corto y estrecho (Fig. 38b); la región interorbital está fuertemente constreñida (Fig. 38d), su anchura es menor de $11.5 \mathrm{~mm}$. En Jalisco se distribuyen ampliamente, principalmente desde la parte centro-este del estado, extendiéndose hacia el occidente y sur-sureste de esta región 3

3. Especie de talla relativamente grande, su longitud total es mayor de $270 \mathrm{~mm}$; la pata trasera siempre es mayor de $36 \mathrm{~mm}$; cresta sagital presente (Fig. 38e). Su distribución se extiende entre los 600 y 3,400 m de altitud, desde la parte central del estado y se extiende hacia al sur-sureste hasta los límites con los estados de Colima y Michoacán, y existe una población aislada en el municipio de Lagos de Moreno. Cratogeomys fumosus 


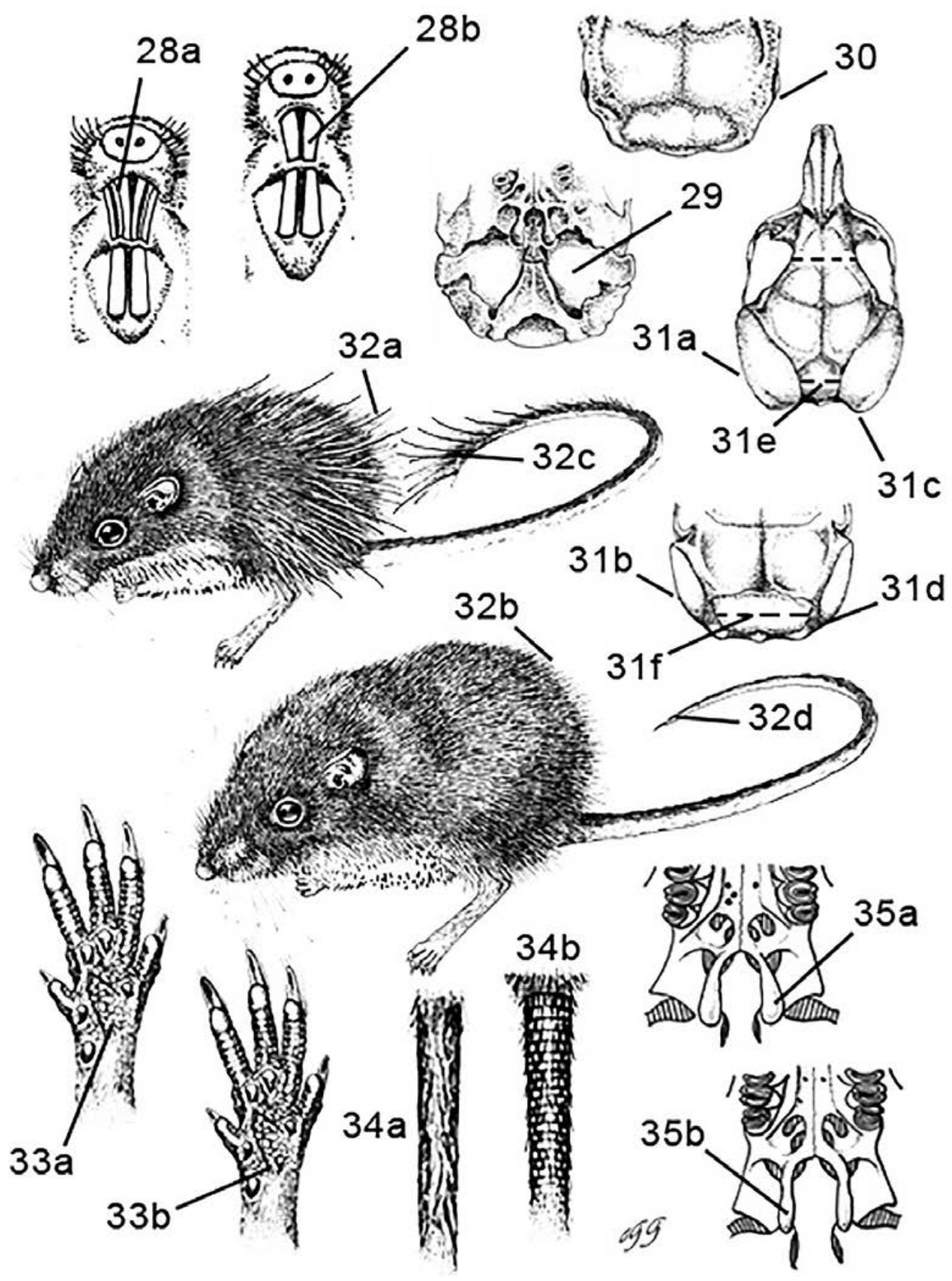

3'. Especie de talla mediana a relativamente pequeña, su longitud total es menor de $270 \mathrm{~mm}$; la pata trasera siempre es menor de $36 \mathrm{~mm}$; cresta sagital ausente (Fig. 38f). Su extensión geográfica se extiende desde el nivel del mar hasta los 3,000 m de altitud en el centro-este del estado, extendiéndose al oeste y sur-suroeste, y existe una población aislada en Mazamitla (Sierra del Tigre) Pappogeomys bulleri 
4. En general el pelaje de estos individuos es relativamente áspero y ralo; presentan una coloración pardo oscuro casi negro; los costados no contrastan con el color del dorso del cuerpo; el vientre con la base del pelo gris oscuro y con las puntas solo levemente más claras. La distribución de esta especie está restringida al norte del estado en la región de Bolaños y probablemente se extiende al oeste y sur de esta región, y a través del cauce del río Santiago cerca del límite con Nayarit..................................... Thomomys atrovarius

4 '. En general el pelaje de estos individuos es relativamente laxo y denso; presentan una coloración pardo castaño; los costados contrastan claramente con el color del dorso del cuerpo; el vientre con la base del pelo gris y las puntas de color leonado. La distribución de esta especie se extiende a través del norte y extremo este de Los Altos, en los límites con los estados de Aguascalientes, Guanajuato y Zacatecas, y probablemente también desde el municipio de Huejucar hasta Totatiche en el noreste de la entidad. Thomomys umbrinus

\section{Clave para los géneros y especies de la familia Cricetidae}

1. Especie de complexión redonda y cola relativamente corta, su longitud es menor del $35 \%$ de la longitud de cabeza y cuerpo (Fig. 39); las orejas son pequeñas y poco conspicuas, ya que se encuentran casi completamente ocultas entre el pelo denso; borde dorsal del foramen infraorbital sin muesca (Fig. 40a); el foramen incisivo es notoriamente menor que la hilera superior de dientes (Fig. 41a); molares con la superficie oclusal plana y un patrón complejo del esmalte en forma de triángulos alternos a un lado y otro del eje longitudinal (Fig. 42a). Su distribución se restringe en los zacatonales de alta montaña que se localizan principalmente al sur y suroeste del estado, y probablemente al noroeste de Magdalena...............................................................Microtus mexicanus

1'. Especie de complexión alargada y cola relativamente larga, su longitud es mayor del $35 \%$ de la longitud de cabeza y cuerpo; las orejas por lo común son grandes y conspicuas, ya que se encuentran casi completamente visibles sobre el pelo; borde dorsal del foramen infraorbital con una muesca dirigida posteriormente (Fig. 40b); el foramen incisivo es igual o claramente mayor que la hilera superior de dientes (Fig. 41b); superficie oclusal de los molares con dos hileras de cúspides arregladas longitudinalmente, o molares de corona plana que disponen más bien de un patrón complejo de pliegues y lofos dispuestos alternadamente (Fig. 42b). Su distribución cubre todos los tipos de vegetación del estado y se localizan principalmente desde el nivel del mar hasta los 3,700 m de altitud.....

2

2. Presentan una mancha ocular oscura que se extiende hasta la base de la nariz y vibrisas (Fig. 43); pelo de la región ventral completamente blanco (Fig. 44a); la cola es monocolor y afelpada, y la porción distal está cubierta por un mechón conspicuo de pelos largos; superficie dorsal de la pata posterior oscura (Fig. 45a); cráneo con los parietales y frontales relativamente amplios (Fig. 46a); el interparietal separa completamente los parietales del occipital (Fig. 46c); 
región supraorbital fuertemente crestada (Fig. 46e). En Jalisco se distribuyen exclusivamente en la costa sur. Nyctomys sumichrasti

2'. No presentan mancha ocular oscura; pelo de la región ventral generalmente con la base oscura (Fig. 44b); la cola por lo común es bicolor y puede estar cubierta con pelo principalmente sobre la región dorsal, y en la parte distal por lo general no existe un mechón conspicuo de pelos largos; superficie dorsal de la pata posterior usualmente clara (Fig. 45b); parietales y frontales relativamente angostos (Fig. 46b); el interparietal no separa completamente los parietales del occipital (Fig. 46d); región supraorbital con los bordes lisos o rara vez con leves protuberancias (Fig. 46f; excepto en Xenomys nelsoni). Se distribuyen en todo el territorio estatal......

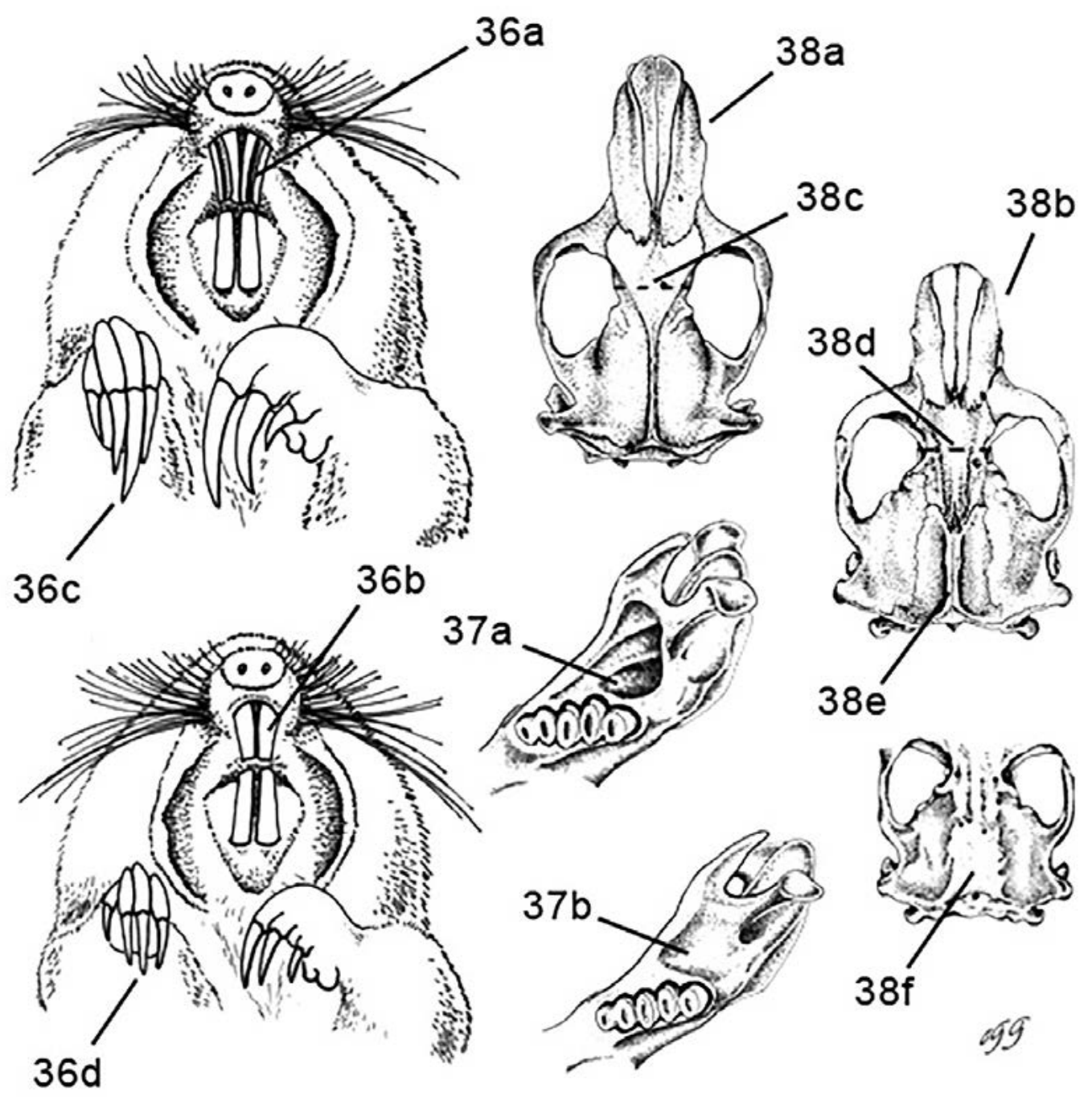

3. Pelaje de la parte superior del cuerpo largo y áspero a bastante hirsuto; la apariencia general de estos individuos es más o menos redondeada con una cabeza aguda y un cuello poco definido (Fig. 47); las orejas son relativamente pequeñas y poco conspicuas; cráneo con el rostro relativamente corto y agudo (Fig. 48a); 
la región interorbital con forma de cuña (Fig. 48c); el arco zigomático converge claramente por su porción anterior, de manera que la parte anterior del cráneo (anterior a la caja craneana) tiene forma triangular (Fig. 48e); palatino con dos fosas postero-laterales profundas y en ocasiones perforadas (Fig. 49a)...............4
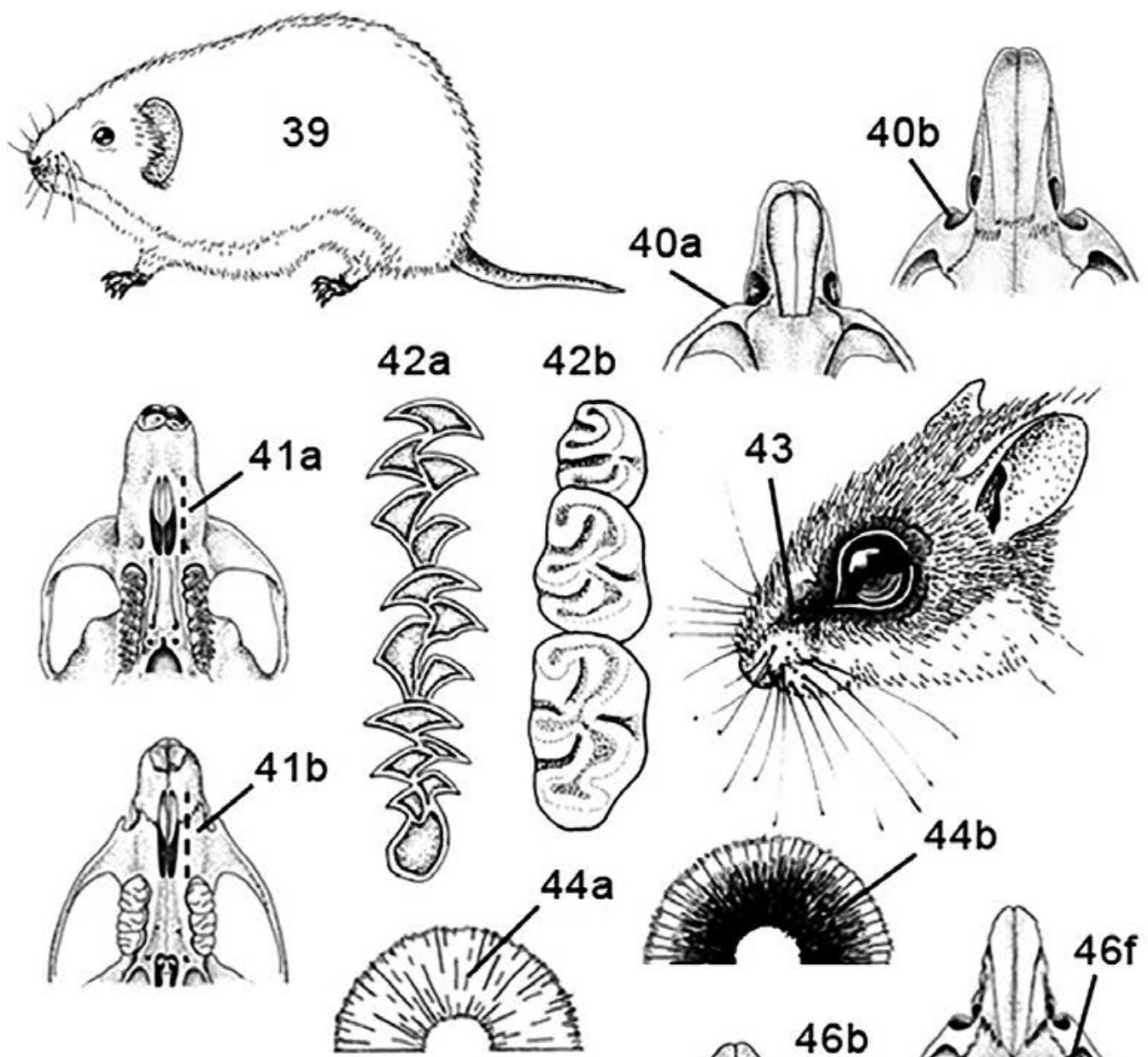
4 
que la base (Fig. 48b); la región interorbital generalmente es redondeada, por lo común en forma de reloj de arena (Fig. 48d); el arco zigomático no converge notoriamente por su parte anterior, de modo que la parte anterior del cráneo (anterior a la caja craneana) no tiene forma triangular (Fig. 48f); palatino sin fosas postero-laterales (Fig. 49b)..... 1

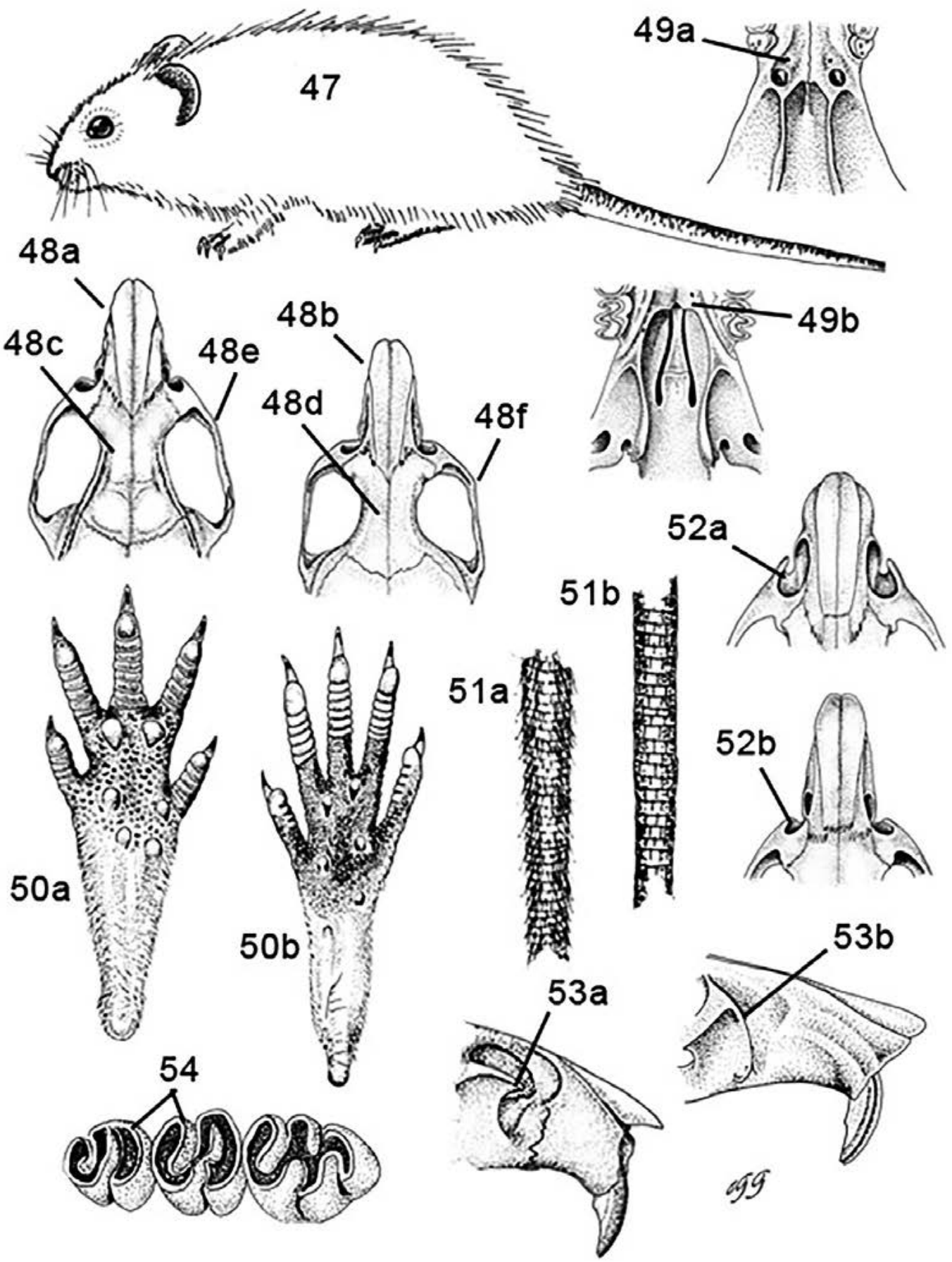

4. Pelaje largo e hirsuto y entremezclado notoriamente con pelos claros, de manera que el pelo adquiere un aspecto canoso; coloración general no claramente bicolor, principalmente el color de las patas no contrasta con la del dorso del 
cuerpo; patas traseras robustas y con los dedos externos relativamente cortos los cuales nunca sobrepasan el nivel de la base de los tres dedos internos (Fig. 50a); la cola por lo general es más corta que la cabeza y el cuerpo, y está cubierta con pelos claramente visibles (Fig. 51a); muesca sobre el borde dorsal del foramen infraorbital profunda, visto dorsalmente (Fig. 52a); parte antero-dorsal de la pared externa del foramen infraorbital o placa zigomática con un proceso espinoso (Fig. 53a); los dos últimos molares muestran una configuración en forma de "S" o "E" (Fig. 54) Sigmodon 5

4 '. Pelaje largo y áspero y sin pelos claros entremezclados; coloración del cuerpo claramente bicolor, principalmente el color de las patas contrasta claramente con la del dorso del cuerpo; patas traseras esbeltas y con los dedos externos relativamente largos, al menos el quinto dedo sobrepasa notoriamente el nivel de la base de los tres dedos internos (Fig. 50b); la cola siempre es más larga que la cabeza y el cuerpo, y está cubierta con pelos poco visibles (Fig. 51b); muesca sobre el borde dorsal del foramen infraorbital moderadamente profunda, visto dorsalmente (Fig. 52b); parte antero-dorsal de la placa zigomática lisa, sin proceso espinoso (Fig. 53b); los dos últimos molares nunca tienen un patrón en forma de "S" o " $\mathrm{E}$ ". .8

5. Especie con la región ventral oscura, de color ante-ocráceo; dorso del cuerpo entremezclado contrastantemente con pelos claros; la cola es monocolor (generalmente negruzca) y está cubierta con abundantes pelos largos, lo cual le da una apariencia no escamosa; cráneo relativamente corto y ancho (Fig. 55a); las fosas palatinas son profundas (Fig. 56a). Su distribución se extiende desde la parte centro-este del estado, hasta la región de Los Altos y norte de la entidad, principalmente en zonas semiáridas Sigmodon fulviventer

$5^{\prime}$. Especie con la región ventral clara, generalmente de color blanquecino; dorso del cuerpo entremezclado no contrastantemente con pelos claros; la cola es bicolor y está cubierta con escasos pelos cortos, lo cual le da una apariencia escamosa; cráneo relativamente largo y angosto (Fig. 55b); las fosas palatinas son poco profundas (Fig. 56b). Su distribución se extiende a todo el estado, desde las tierras bajas tropicales a través de la vertiente del Pacifico, hasta el zacatonal alpino de la sima de las montañas más altas de la entidad. 6

6. Son individuos de pelo relativamente hispido; dorso del cuerpo impregnado de un lustroso color ante grisáceo; basioccipital largo y angosto (Fig. 57a); las bulas auditivas son alargadas (Fig. 57c). Se distribuyen en casi todo el estado...........7

6'. Son individuos de pelo relativamente laxo; dorso del cuerpo impregnado de un deslustrado color pardo amarillento o anaranjado; basioccipital corto y ancho (Fig. 57b); las bulas auditivas son estrechas y redondeadas (Fig. 57d). Su distribución está restringida al occidente y sur de la entidad Sigmodon alleni

7. Longitud de la pata trasera mayor de $34 \mathrm{~mm}$; cuerpo con el dorso de color ante canela pálido o ante grisáceo; parte superior y lados de la nariz teñidos 
conspicuamente de pardo herrumbroso o ante; superficie dorsal de la pata trasera de color gris pardusco; espina posterior del palatino ausente o ligeramente desarrollada (Fig. 58a); el foramen oval es relativamente pequeño menor que la mitad del diámetro del tercer molar superior (Fig. 58c); nasales con los bordes laterales generalmente rectos o ligeramente cóncavos (Fig. 59a). En el estado se distribuyen extensamente (excepto en Los Altos Norte) y cubren una gran variedad de condiciones ambientales, desde el nivel del mar hasta aproximadamente los $2,200 \mathrm{~m}$ de altitud.

Sigmodon mascotensis

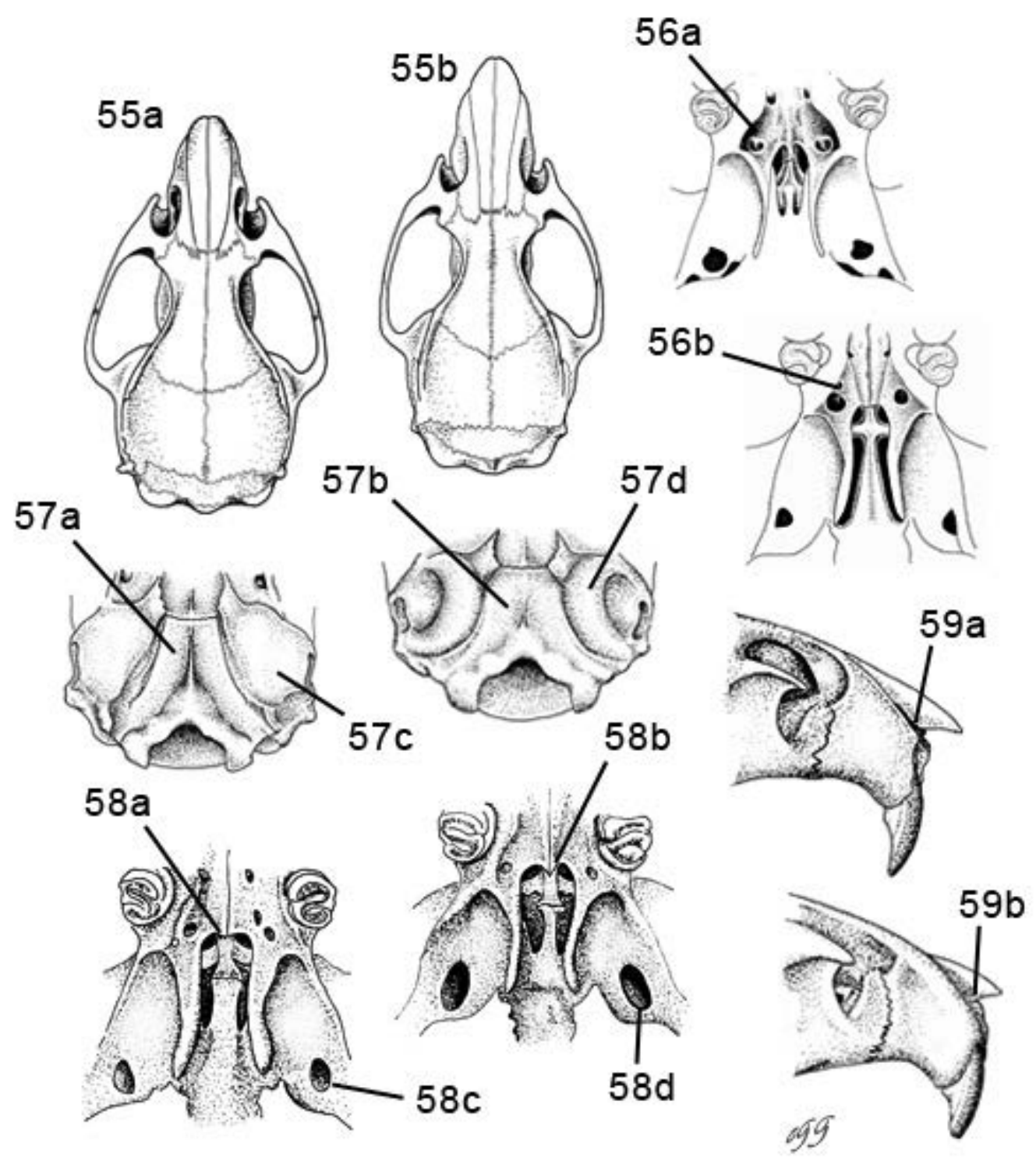

$7^{\prime}$. Longitud de la pata trasera menor de $34 \mathrm{~mm}$; cuerpo con el dorso de color ante grisáceo claro; parte superior y lados de la nariz teñidos tenuemente de amarillento; superficie dorsal de la pata trasera de color gris plateado; espina posterior del palatino bien desarrollada (Fig. 58b); el foramen oval es relativamente grande, igual o mayor que la mitad del diámetro del tercer molar superior (Fig. 58d); 
nasales con los bordes laterales cóncavos (Fig. 59b). En Jalisco se distribuyen desde la parte centro-sur, extendiéndose hacia toda la región de Los Altos y norte del estado, principalmente en altitudes mayores a los 1,200 m

Sigmodon hispidus

8. Individuos de talla relativamente pequeña $(<210 \mathrm{~mm})$ y de complexión esbelta (Fig. 60a); longitud de la pata trasera menor de $25 \mathrm{~mm}$; el cráneo es de estructura delicada (Fig. 61a); caja craneana redondeada (Fig. 61c); las crestas temporales y supraorbitales están ausentes (Fig. 61e). Se distribuyen en altitudes bajas $(<1,400 \mathrm{~m})$ a través de la vertiente del Pacífico y extremo sureste del estado..................................................................... Oligoryzomys fulvescens

$8^{\prime}$. Individuos de talla relativamente grande $(>210 \mathrm{~mm})$ y de complexión robusta (Fig. 60b); longitud de la pata trasera mayor de 25 mm; el cráneo es de estructura maciza (Fig. 61b); caja craneana alargada (Fig. 61d); las crestas temporales y supraorbitales están presentes y bien desarrolladas (Fig. 61f). Se distribuyen desde el centro-este hasta el occidente y sur de la entidad, principalmente desde el nivel del mar hasta aproximadamente los 2,200 m de altitud,........Oryzomys 9

9. Pata trasera con pelos digitales que se proyectan notoriamente más allá del extremo superior de las garras de los tres dedos más largos (Fig. 62a); son de tamaño pequeño generalmente su longitud total es menor de $245 \mathrm{~mm}$; el borde post-palatal está en ángulo truncado, de manera que el borde adquiere una configuración más o menos en forma trapezoidal (Fig. 63a); margen posterior del foramen incisivo generalmente no se extiende hasta el nivel de la parte anterior del primer molar superior (Fig. 64a). Su distribución se extiende a través de la planicie costera y las montañas aledañas...........................Oryzomys melanotis

9'. Pata trasera con pelos digitales que no se proyectan más allá del extremo superior de las garras de los tres dedos más largos (Fig. 62b); son de talla grande generalmente su longitud total es mayor de $245 \mathrm{~mm}$; el borde post-palatal está en ángulo re-entrante, de modo que el borde adquiere una configuración en forma de "V" (Fig. 63b); el margen posterior del foramen incisivo se extiende hasta el nivel de la parte anterior el primer molar superior (Fig. 64b). Su distribución se extiende desde del centro-este de la entidad, extendiéndose hasta el oeste y sur encontrando su límite en el Pacífico y los estados de Colima, Michoacán y Nayarit. 10

10. Especie de talla mediana, longitud total entre 195 a $305 \mathrm{~mm}$; pata trasera entre 26 a 35 mm de longitud; longitud de la cola entre 100 a 165 mm; longitud occipitonasal entre 26 a $34 \mathrm{~mm}$; los molares en esta especie son relativamente esbeltos en comparación al tamaño del hueso palatal (Fig. 65a). Se distribuyen ampliamente en las tierras bajas del occidente (ladera oeste de la Sierra Madre del Sur) y extremo sur-sureste del estado, principalmente por debajo de los 1,600 m de altitud...............................................................Oryzomys mexicanus

10'. Especie de talla grande, longitud total entre 240 a $345 \mathrm{~mm}$; pata trasera entre 34 a 38 mm de longitud; longitud de la cola entre 140 a 170 mm; longitud occipitonasal entre 31 a $34 \mathrm{~mm}$; los molares en esta especie son 
relativamente robustos en comparación al tamaño del hueso palatal (Fig. 65b). Su distribución se restringe en áreas de elevaciones moderadas de toda la parte central del estado, por lo común entre los 1,200 a 2,200 m de altitud......

Oryzomys albiventer

11. Superficie anterior de los incisivos superiores con un surco longitudinal (Fig. 66a)......

Reithrodontomys 12

11 '. Superficie anterior de los incisivos superiores sin surco longitudinal (Fig. 66b)...

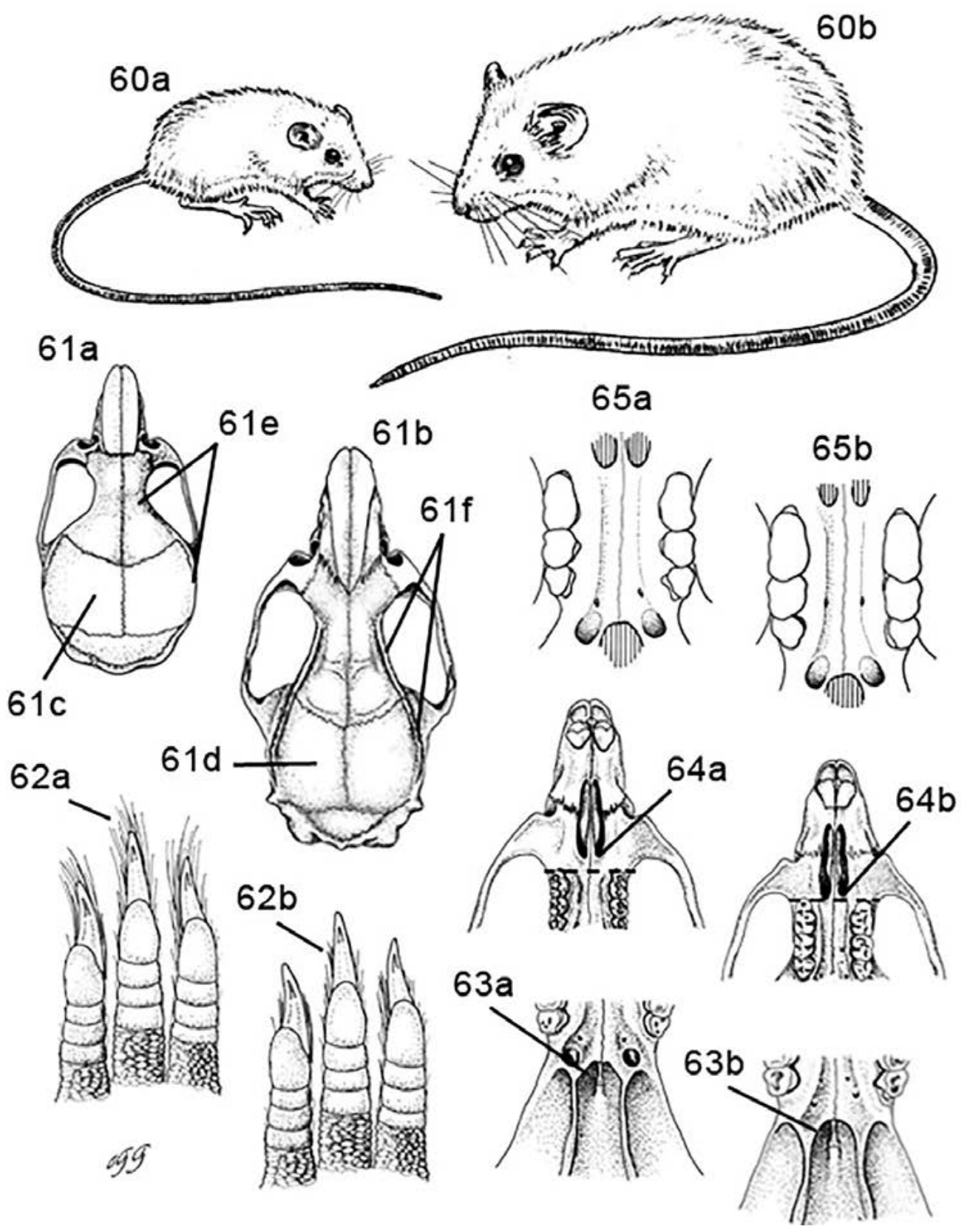

12. Cola monocolor; superficie dorsal de la pata trasera oscura hasta la base de los dedos (Fig. 67a); el foramen incisivo es relativamente corto, es menor del 18 $\%$ de la longitud occipitonasal (Fig. 68a); porción anterior del arco zigomático de estructura delicada (Fig. 69a); parte posterior del cráneo (posterior a la 
constricción interorbital) notoriamente más largo que la porción anterior (Fig. 69c); la caja craneana es muy amplia, su anchura es mayor que la del arco zigomático (Fig. 69e); muesca sobre la parte dorsal del foramen infraorbital no distintiva (Fig. 69g); placa zigomática angosta, su anchura es igual que el de la fosa mesopterigoidea (Fig. 70a); patrón molar complejo, las cúspides accesorias están presentes usualmente en todos los molares (Fig. 71a); las cúspides principales particularmente las de los molares superiores están casi opuestas en posición (Fig. 71c). Esta especie se conoce de una sola localidad en la Sierra VolcánNevado de Colima al sur de la entidad Reithrodontomys mexicanus

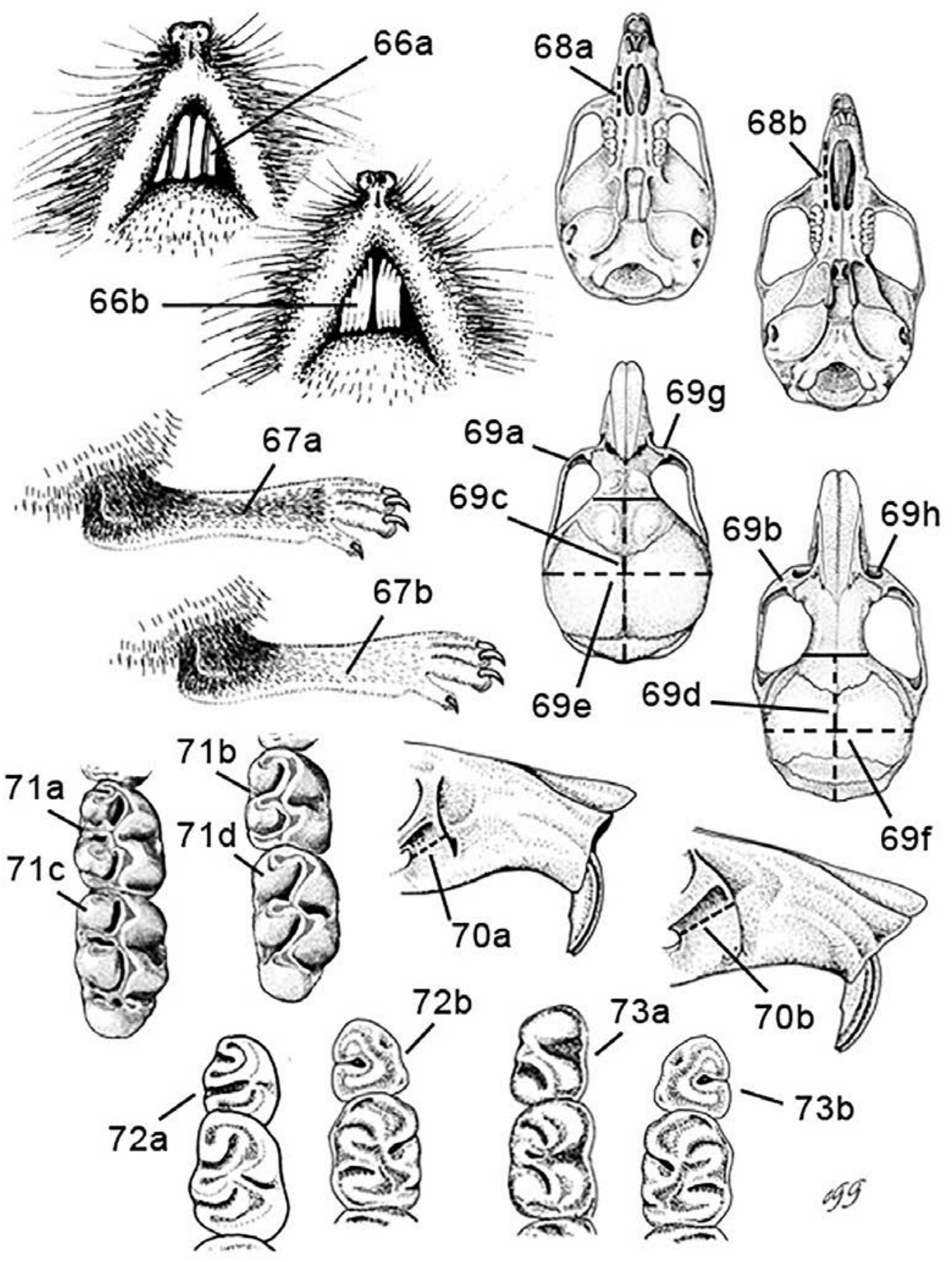


$12^{\prime}$. Cola por lo común bicolor; la superficie dorsal de la pata trasera generalmente es clara hasta la base de los dedos (Fig. 67b); el foramen incisivo es relativamente largo, es mayor del $18 \%$ de la longitud occipitonasal (Fig. 68b); porción anterior del arco zigomático de estructura maciza (Fig. 69b); parte posterior del cráneo (posterior a la constricción interorbital) igual o notoriamente más corta que la porción anterior (Fig. 69d); la caja craneana es angosta, su anchura es menor que la del arco zigomático (Fig. 69f); muesca sobre la parte dorsal del foramen infraorbital distintiva (Fig. 69h); placa zigomática amplia, su anchura es mayor que el de la fosa mesopterigoidea (Fig. 70b); patrón molar simple, las cúspides accesorias generalmente están ausentes (Fig. 71b); las cúspides principales particularmente las de los molares superiores están más bien alternas en posición (Fig. 71d). Se distribuyen en todo el estado

13. Individuos de talla relativamente pequeña, su longitud total es menor de $170 \mathrm{~mm}$; la longitud de la cola generalmente es menor de $90 \mathrm{~mm}$; longitud occipitonasal menor de $23 \mathrm{~mm}$; anchura de la caja craneana menor de $10.5 \mathrm{~mm}$.

13'. Individuos de talla mediana a relativamente grande, su longitud total es mayor de $170 \mathrm{~mm}$; el largo de la cola generalmente es mayor de $90 \mathrm{~mm}$; longitud occipitonasal mayor de $23 \mathrm{~mm}$; anchura de la caja craneana mayor de $10.5 \mathrm{~mm}$

14. La cola es relativamente larga, su longitud generalmente es mayor del $120 \%$ de la longitud de cabeza y cuerpo; la coloracion del dorso varía de amarillo pardusco a canela; pabellón auricular con la parte interna revestida de numerosos pelos cortos de color amarillento o rojizo; en el tercer molar superior el primer pliegue primario es tan largo o más que el segundo pliegue primario y el pliegue mayor está bien desarrollado, algunas veces continúa hasta el primer pliegue primario, de manera que la superficie oclusal del diente adquiere una configuración en forma de "E" (Fig. 72a); en el tercer molar inferior el pliegue mayor es al menos tan largo que el primer pliegue primario, por lo cual la superficie oclusal del diente tiene una forma de "S" (Fig. 73a). En Jalisco se distribuyen desde la parte baja tropical a través de la vertiente del Pacifico hasta las zonas templadas de altitudes moderadas $(<2,200 \mathrm{~m})$, y en la región semiárida del estado. Reithrodontomys fulvescens

14'. La cola es relativamente corta, su longitud generalmente es menor del $120 \%$ de la longitud de cabeza y cuerpo; el color del dorso varía de pardo a ante grisáceo; pabellón auricular con la parte interna cubierta con escasos pelos cortos de color negro y canela; en el tercer molar superior el primer pliegue primario es más corto que el segundo pliegue primario y el pliegue mayor es indistinto (a lo mucho amplio), de modo que la superficie oclusal del diente adquiere una configuración en forma de "C" (Fig. 72b); en el tercer molar inferior el pliegue mayor es más corto que el primer pliegue primario, con ello la superficie oclusal del diente obtiene una forma de "C" (Fig. 73b). En Jalisco se distribuyen principalmente en las áreas templadas (excepto las de la Sierra Madre del Sur) y semiáridas.........15 
15. Cola generalmente mayor del $116 \%$ de la longitud de cabeza y cuerpo; el dorso del cuerpo es de color pardo rojizo; vientre oscuro, de color ante oscuro o canela; la muesca sobre el borde dorsal del foramen infraorbital es poco profunda (Fig. 74a). Se distribuyen en las zonas altas templadas $(>1,800 \mathrm{~m}$ de altitud), desde el norte hasta la Sierra Volcán-Nevado de Colima al sur del estado.

Reithrodontomys zacatecae

15. Cola por lo común menor del $116 \%$ de la longitud de cabeza y cuerpo; el dorso del cuerpo varía de pardo oscuro a ante grisáceo; vientre claro, de color blanco o ante blanquecino; la muesca sobre el borde dorsal del foramen infraorbital es profunda (Fig. 74b). Se distribuyen desde los valles y zona montañosa del centro del estado, hasta la parte semiárida de Los Altos, principalmente habitan en altitudes por arriba de los 1,200 m Reithrodontomys megalotis

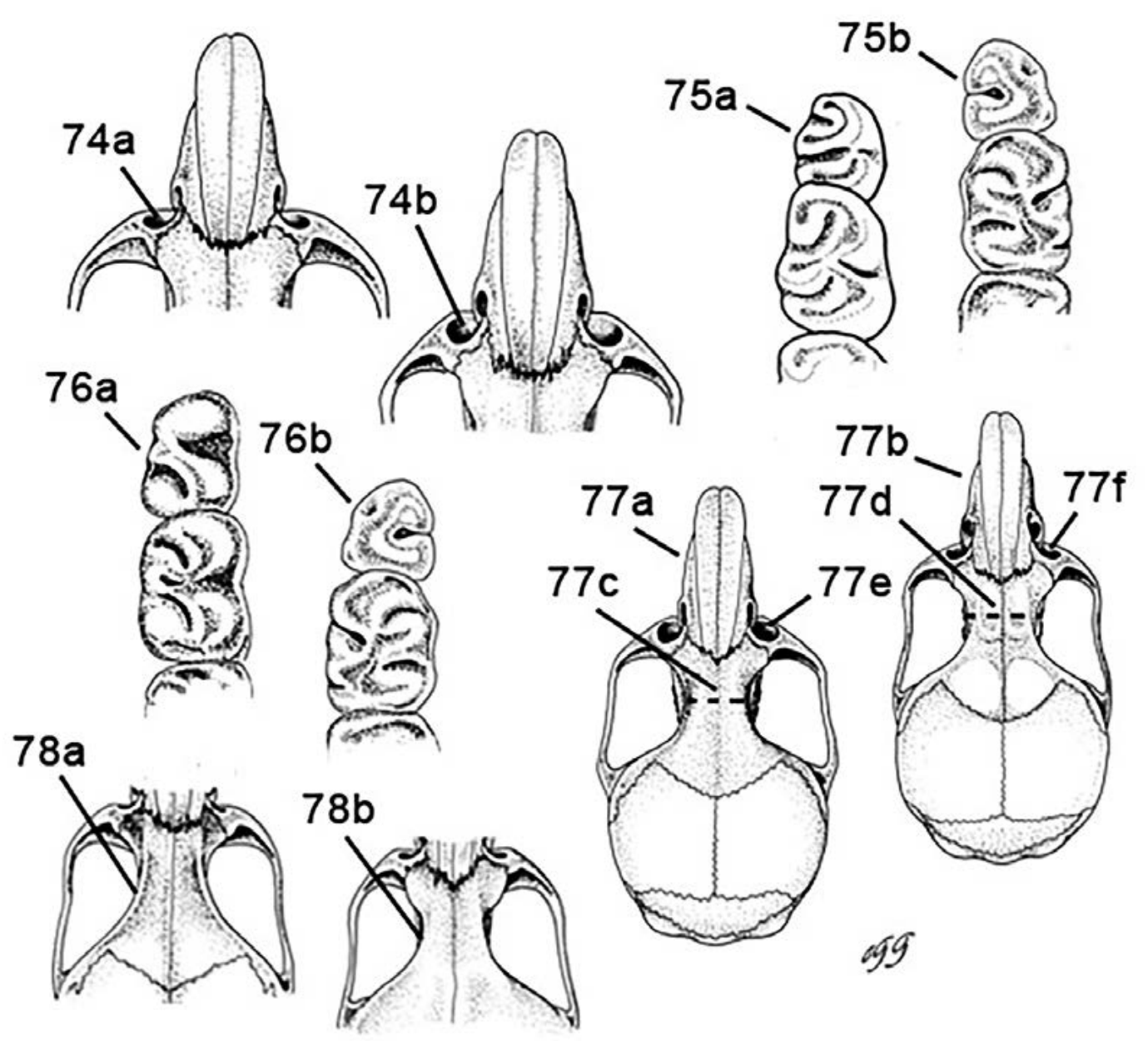

16. El dorso del cuerpo varía de amarillo pardusco a canela; la parte ventral por lo común es clara, de color blanquecino o de un tenue canela pálido; en el tercer molar superior el primer pliegue primario es tan largo o más que el segundo pliegue primario y el pliegue mayor está bien desarrollado, algunas veces continúa hasta el primer pliegue primario, de modo que la superficie oclusal del 
diente adquiere una configuración en forma de "E" (Fig. 75a); en el tercer molar inferior el pliegue mayor es al menos tan largo que el primer pliegue primario, con esto la superficie oclusal del diente tiene una forma de "S" (Fig. 76a). Su distribución cubre casi todo el territorio estatal, principalmente en elevaciones por debajo de los 2,200 $\mathrm{m}$ de altitud. 18

16'. El dorso del cuerpo varía de ante anaranjado a canela; la región ventral por lo común es oscura, de color canela o canela rosáceo; en el tercer molar superior el primer pliegue primario es más corto que el segundo pliegue primario y el pliegue mayor es indistinto (a lo mucho amplio), por lo cual la superficie oclusal del diente tiene una forma de " $\mathrm{C}$ " (Fig. 75b); en el tercer molar inferior el pliegue mayor es más corto que el primer pliegue primario, de manera que la superficie oclusal del diente adquiere una configuración en forma de "C" (Fig. 76b). Su distribución está restringida al sur y sur-suroeste de la entidad, principalmente en la parte alta templada que se ubica por arriba de los 2,000 m de altitud..........17

17. Cola bicolor y relativamente corta (claramente revestida de pelos largos), su longitud generalmente es menor del 128 \% de la longitud de cabeza y cuerpo; dorso del cuerpo de color dorado o ante anaranjado brilloso; la parte interna de las orejas está cubierta de pelos negros; cráneo con el rostro relativamente largo y angosto (Fig. 77a); la región interorbital está fuertemente constreñida (Fig. 77c); la muesca sobre la parte dorsal del foramen infraorbital es profunda (Fig. 77e). En Jalisco la distribución de esta especie se restringe en la sima de la Sierra Volcán-Nevado de Colima al sur del estado, principalmente en altitudes mayores a los 2,700 m Reithrodontomys chrysopsis

17'. Cola por lo común ligeramente bicolor y relativamente larga (escasamente revestida de pelos cortos), su longitud generalmente es mayor del $128 \%$ de la longitud de cabeza y cuerpo; el dorso del cuerpo en general es de color canela; la parte interna de las orejas está cubierta al menos con escasos pelos de color ante; cráneo con el rostro relativamente corto y ancho (Fig. 77b); el área interorbital no está constreñida (Fig. 77d); la muesca sobre la parte dorsal del foramen infraorbital es poco profunda (Fig. 77f). En Jalisco la distribución de esta especie se extiende al sur y sur-suroeste, principalmente por debajo de los 2,700 m sobre el nivel del mar. Reithrodontomys sumichrasti

18. Especie de gran tamaño, su longitud total principalmente es mayor de 180 mm; longitud de la cola mayor de $100 \mathrm{~mm}$; el pelaje del dorso del cuerpo está entremezclado contrastantemente con pelos negros, de modo que el dorso adquiere un aspecto rayado; cola monocolor, o en ocasiones con la porción ventral levemente más pálida; la pata trasera generalmente es oscura sobre la superficie dorsal; el borde supraorbital está afilado (Fig. 78a). Se distribuyen en elevaciones bajas (900-1,200 m), principalmente sobre la parte tropical que se sitúa al norte del occidente de la entidad en el límite con el estado de Nayarit................................. Reithrodontomys hirsutus

18 '. Especie de talla mediana a relativamente pequeña, su longitud total principalmente es menor de $180 \mathrm{~mm}$; longitud de la cola menor de $100 \mathrm{~mm}$; el pelaje del dorso 
del cuerpo está entremezclado ligeramente con pelos negros, de modo que el dorso no adquiere un aspecto rayado; cola marcadamente bicolor; la pata trasera siempre es clara sobre la superficie dorsal; el borde supraorbital está redondeado o en ocasiones elevado pero no afilado (Fig. 78b). Se distribuyen en casi todo el estado y ocupan diferentes tipos de vegetación, desde el nivel del mar hasta aproximadamente los 2,200 m de altitud. Reithrodontomys fulvescens

19. Por lo común son especies de talla grande, su longitud total es mayor de 290 $\mathrm{mm}$; largo de la cabeza y el cuerpo mayor de $120 \mathrm{~mm}$; la cola y las patas son relativamente robustas; molares de corona plana (cúspides no evidentes) y ángulos re-entrantes profundos en forma de "V" en ambos lados de los dientes (Fig. 79a). 20

19'. Son especies de talla pequeña, su longitud total es menor de $290 \mathrm{~mm}$; largo de la cabeza y el cuerpo menor de $120 \mathrm{~mm}$; la cola y las patas son relativamente esbeltas; molares más bien con un patrón de cúspides arregladas en dos pares de hileras longitudinales (Fig. 79b)..... .26

20. Presentan una mancha blanca notoriamente definida sobre cada ojo; vientre con el pelo totalmente blanco; la cola es monocolor y por lo común es ligeramente más corta que la cabeza y el cuerpo; el cráneo con crestas supraorbitales marcadamente elevadas y proyectadas lateralmente (Fig. 80a); las bulas auditivas están grandemente dilatadas, alargadas antero-posteriormente y dispuestas paralelamente en relación al eje longitudinal del cráneo (Fig. 81a). Su distribución está restringida al bosque tropical caducifolio que se ubica en la vertiente sur del Pacífico de Jalisco............................................................... Xenomys nelsoni

20'. No presentan manchas blancas sobre los ojos; vientre con la base del pelo usualmente oscura; la cola por lo general es bicolor y es más larga que la cabeza y el cuerpo; el cráneo con los bordes de los frontales lisos o en ocasiones desarrollan pequeñas protuberancias (Fig. 80b); las bulas auditivas no están dilatadas y su longitud no es notoriamente mayor que su anchura, y están dispuestas inclinadamente en relación al eje longitudinal del cráneo (Fig. 81b). Se distribuyen en casi todo el estado y habitan condiciones ambientales muy diversas. 21

21. Son individuos de talla grande, su longitud total es mayor de $260 \mathrm{~mm}$; el largo de la pata trasera generalmente es mayor de $30 \mathrm{~mm}$; en el tercer molar superior se presentan dos ángulos re-entrantes del lado externo y uno sobre el lado interno (Fig. 82a); el segundo molar inferior tiene dos ángulos re-entrantes sobre cada lado (Fig. 83a); y el tercer molar inferior presenta solo un ángulo por lado (Fig. 83c) 23

21. Son individuos de tamaño pequeño, su longitud total es menor de $260 \mathrm{~mm}$; la longitud de la pata trasera usualmente es menor de $30 \mathrm{~mm}$; molares con pliegues simplificados, de manera que el tercer molar superior presenta solo un ángulo re-entrante estrecho del lado externo (Fig. 82b); el segundo molar inferior tiene un ángulo re-entrante sobre cada lado (Fig. 83b); y en el tercer molar inferior está presente solo un ángulo bastante abierto sobre el lado interno (Fig. 83d) 
22. Superficie dorsal de la pata trasera oscura; la cola es ligeramente bicolor y la parte apical nunca es blanca; muesca sobre la región dorsal del foramen infraorbital distintiva (Fig. 84a). Se distribuyen al sur del estado Nelsonia goldmani

22'. Superficie dorsal de la pata trasera clara; la cola es bicolor y la parte apical generalmente es blanca; muesca sobre la región dorsal del foramen infraorbital no distintiva (Fig. 84b). Se distribuyen al norte del estado. Nelsonia neotomodon

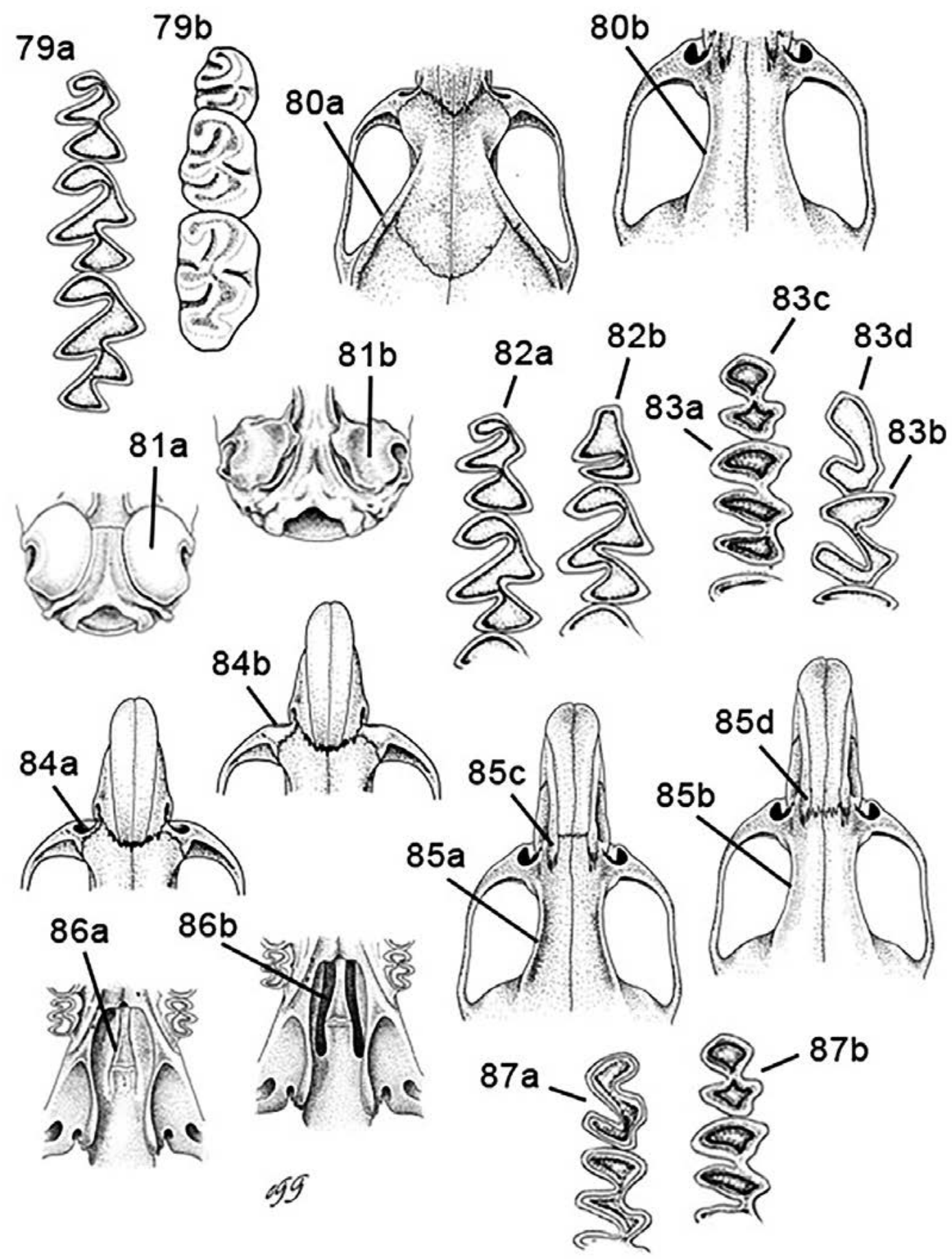


23. Son individuos de talla mediana a relativamente grande, su longitud total es entre 370 a $480 \mathrm{~mm}$; longitud de la pata trasera entre 37 a $45 \mathrm{~mm}$; el rostro es de una tonalidad más pálida que el de la coloración general del cuerpo; la cola por lo común es monocolor y está revestida escasamente de pelos cortos; el cráneo con las protuberancias supraorbitales claramente desarrolladas (Fig. 85a); porciones ascendentes de la región dorsal del premaxilar se extienden más allá de la parte posterior de los nasales (Fig. 85c); las vacuidades esfenopalatinas están cerradas (Fig. 86a); tercer molar inferior con la superficie oclusal en forma de "S" (Fig. 87a). Se distribuyen principalmente en la parte tropical que se extiende desde el centro-este hasta la costa y sureste de la entidad. Hodomys alleni

$23^{\prime}$. Son individuos de talla mediana a relativamente pequeña, longitud total entre 285 a $405 \mathrm{~mm}$; longitud de la pata trasera entre 30 a $41 \mathrm{~mm}$; el rostro por lo común es de una tonalidad similar a la coloración general del cuerpo; la cola es ligera o marcadamente bicolor y está cubierta abundantemente de pelos largos o cortos; cráneo con los bordes de los frontales lisos o rara vez provistos con tenues protuberancias (Fig. 85b); porciones ascendentes de la región dorsal del premaxilar se extienden hasta el mismo nivel de la parte posterior de los nasales (Fig. 85d); las vacuidades esfenopalatinas están abiertas (Fig. 86b); la superficie oclusal del tercer molar inferior nunca presenta una configuración en forma de "S" (Fig. 87b). Se distribuyen en casi todo el territorio estatal (excepto en la costa sur) y se les encuentra en todos los principales tipos de ecosistemas.

24. Largo de la cabeza y el cuerpo menor de $185 \mathrm{~mm}$; la longitud de la pata trasera generalmente es menor de $37 \mathrm{~mm}$; presentan por lo común una mancha de color salmón o ante ocráceo sobre la región pectoral y/o lado interno de las axilas; el cráneo muestra la región interorbital fuertemente constreñida $(<5.6$ $\mathrm{mm}$ ), los bordes lisos y una configuración con forma de reloj de arena (Fig. 88a); vómer con una muesca maxilo-vomerine (Fig. 89a); ángulo re-entrante antero-interno del primer molar superior profundo (Fig. 90a). Su distribución se extiende desde el nivel del mar en la costa norte, hasta los bosques templados de alta montaña de la parte más alta del estado, excepto por la región semiárida de la entidad. Neotoma mexicana

24'. Largo de la cabeza y el cuerpo mayor de $185 \mathrm{~mm}$; la longitud de la pata trasera es mayor de $37 \mathrm{~mm}$; presentan por lo común una mancha completamente blanca sobre la región pectoral; el cráneo muestra la región interorbital relativamente amplia (> $5.6 \mathrm{~mm}$ ), los bordes en ocasiones con ligeras protuberancias y una configuración más o menos en forma de cuña (Fig. 88b); vómer sin muesca maxilo-vomerine (Fig. 89b); ángulo re-entrante antero-interno del primer molar superior somero (Fig. 90b). Se distribuyen exclusivamente en la parte semiárida y tropical que se ubica en Los Altos y norte del estado. .25

25. Parte superior del cuerpo de color ante ocráceo o cremoso, excepto por el rostro que está impregnado de gris; individuos de pelo relativamente largo y suave; la cola es marcadamente bicolor y está cubierta de abundantes pelos largos; 
en esta especie la fosa mesopterigoidea es estrecha (Fig. 91a); las vacuidades esfenopalatinas son muy amplias (Fig. 91c). Su distribución comprende la parte semiárida de Los Altos y norte del estado. Neotoma leucodon

$25^{\prime}$. Parte superior del cuerpo de color canela pálido; individuos de pelo relativamente corto y áspero; la cola es ligeramente bicolor y está cubierta de escasos pelos cortos; en esta especie la fosa mesopterigoidea es amplia (Fig. 91b); las vacuidades esfenopalatinas son muy estrechas, están casi completamente cerradas (Fig. 91d). Su distribución está restringida a la parte tropical seca y áreas aledañas del norte de la entidad Neotoma palatina

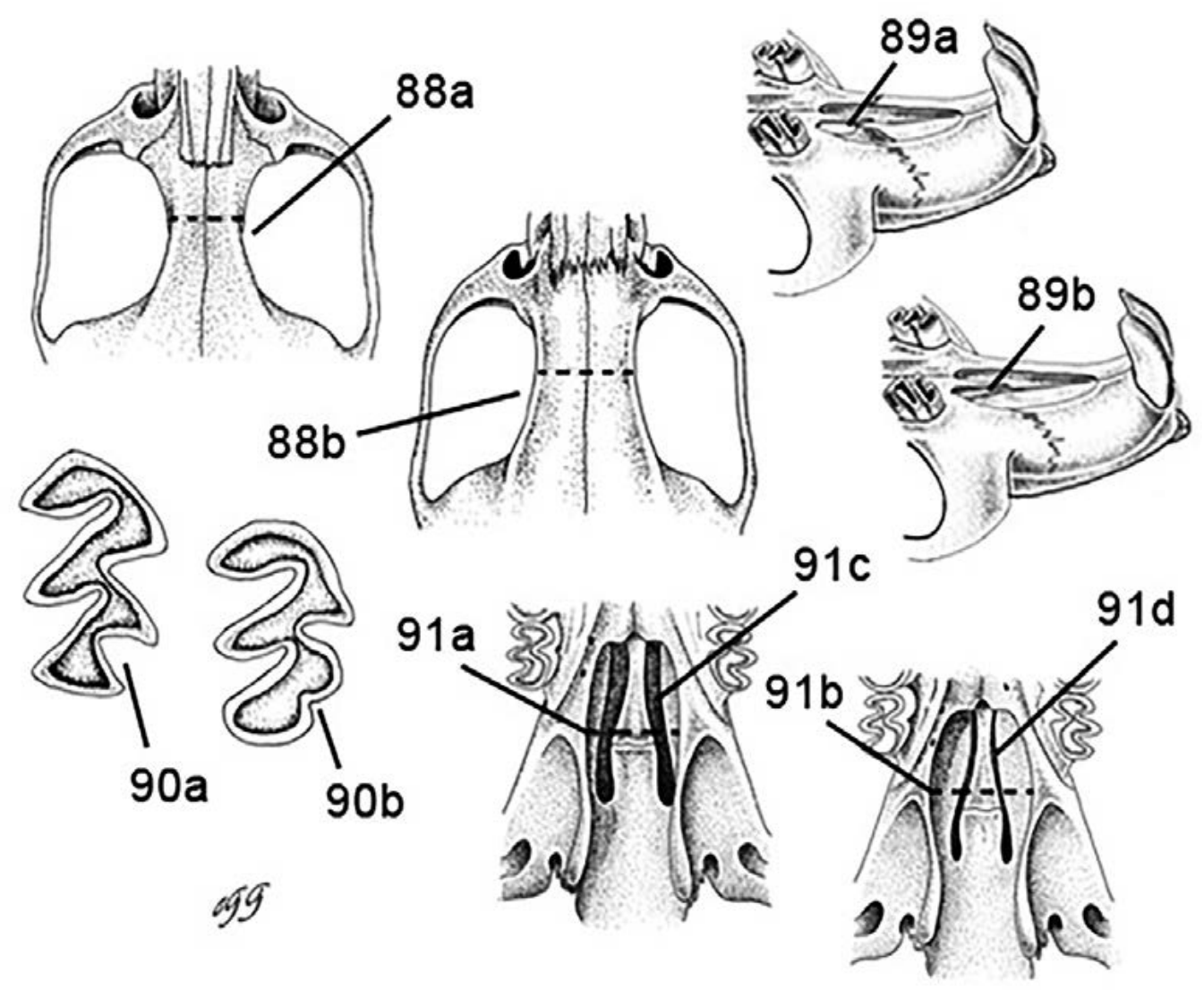

26. Son individuos de talla pequeña, su longitud total es menor de $170 \mathrm{~mm}$; la cola es relativamente corta $(<80 \mathrm{~mm})$, es notoriamente menor que la cabeza y el cuerpo (Fig. 92a); longitud occipitonasal menor de $26 \mathrm{~mm}$.

26 '. Son individuos de talla mediana a considerablemente grande, su longitud total es mayor de $170 \mathrm{~mm}$; la cola es relativamente larga $(>80 \mathrm{~mm})$, por lo común es igual o claramente mayor que la cabeza y el cuerpo (Fig. 92b); longitud occipitonasal usualmente mayor de $26 \mathrm{~mm}$..... ..3

27. En general son de talla mediana $(>136 \mathrm{~mm}$ ) y de cuerpo claramente bicolor; el largo de la cabeza y el cuerpo es principalmente mayor de 80 mm; longitud de la 
pata trasera mayor de $18.5 \mathrm{~mm}$; la cola es robusta y marcadamente bicolor, y está cubierta de abundantes pelos largos los cuales forman una estrecha y definida línea dorsal oscura (Fig. 93a); las orejas son grandes y conspicuas, y tienen forma ovalada (Fig. 94a); el proceso coronoide está levemente desarrollado (Fig. 95a; excepto en Onychomys arenicola).... 29

27 '. En general son de talla muy pequeña $(<136 \mathrm{~mm})$ y de cuerpo levemente bicolor; el largo de la cabeza y el cuerpo es menor de $80 \mathrm{~mm}$; longitud de la pata trasera menor de $18.5 \mathrm{~mm}$; la cola es esbelta y ligeramente bicolor, y está revestida de escasos pelos cortos los cuales nunca forman una definida línea dorsal oscura (Fig. 93b); las orejas son pequeñas y poco conspicuas, y tiene forma redondeada (Fig. 94b); el proceso coronoide está bien desarrollado, surge como una saliente triangular que se extiende casi tan alto como el proceso articular (Fig. 95b)....... Baiomys 28

28.Longitud total generalmente mayor de $120 \mathrm{~mm}$; la longitud de la pata trasera es igual o mayor de $16 \mathrm{~mm}$; el contorno dorsal del cráneo es uniformemente convexo, se curva gradualmente hacia el punto más anterior de los nasales (Fig. 96a); longitud occipitonasal mayor de $19 \mathrm{~mm}$; la anchura zigomática es igual o mayor de $10 \mathrm{~mm}$. Se distribuyen generalmente en áreas tropicales Baiomys musculus

28 '. Longitud total generalmente menor de $120 \mathrm{~mm}$; la longitud de la pata trasera es menor de $16 \mathrm{~mm}$; el contorno dorsal del cráneo más bien se hunde ventralmente a la altura de la sutura fronto-parietal (Fig. 96b); longitud occipitonasal menor de $19 \mathrm{~mm}$; anchura zigomática menor de $10 \mathrm{~mm}$. Se distribuyen principalmente en zonas templadas y semiáridas Baiomys taylori

29. Cola robusta con forma de mazo y con la parte apical por lo común completamente blanca (Fig. 97a); planta del pie trasero desde los tubérculos hasta el talón cubierta abundantemente de pelo; las garras de las patas anteriores son relativamente grandes; el proceso coronoide está bien desarrollado, surge como una saliente triangular que se extiende casi tan alto como el proceso articular (Fig. 98a); molares con un patrón simple, las cúspides accesorias están ausentes (Fig. 99a); cuando no existe desgaste considerable, las cúspides principales son altas y cónicas (Fig. 99c). Su distribución se localiza en la parte semiárida de la región Altos Norte al extremo este-noreste de la entidad. .Onychomys arenicola

29'. Cola relativamente esbelta y con el ápice igual al resto de la cola (Fig. 97b); planta del pie trasero desde los tubérculos hasta el talón cubierta escasamente de pelo; las garras de las patas anteriores son comparativamente pequeñas; el proceso coronoide está levemente desarrollado (Fig. 98b); molares con un patrón complejo, las cúspides accesorias están presentes principalmente en los pliegues externos de los dos primeros molares superiores (Fig. 99b); cuando no existe desgaste considerable, las cúspides principales son bajas y redondeadas (Fig. 99d). Su distribución se localiza en casi todo el estado y habitan en diversas condiciones ambientales. Peromyscus 30 

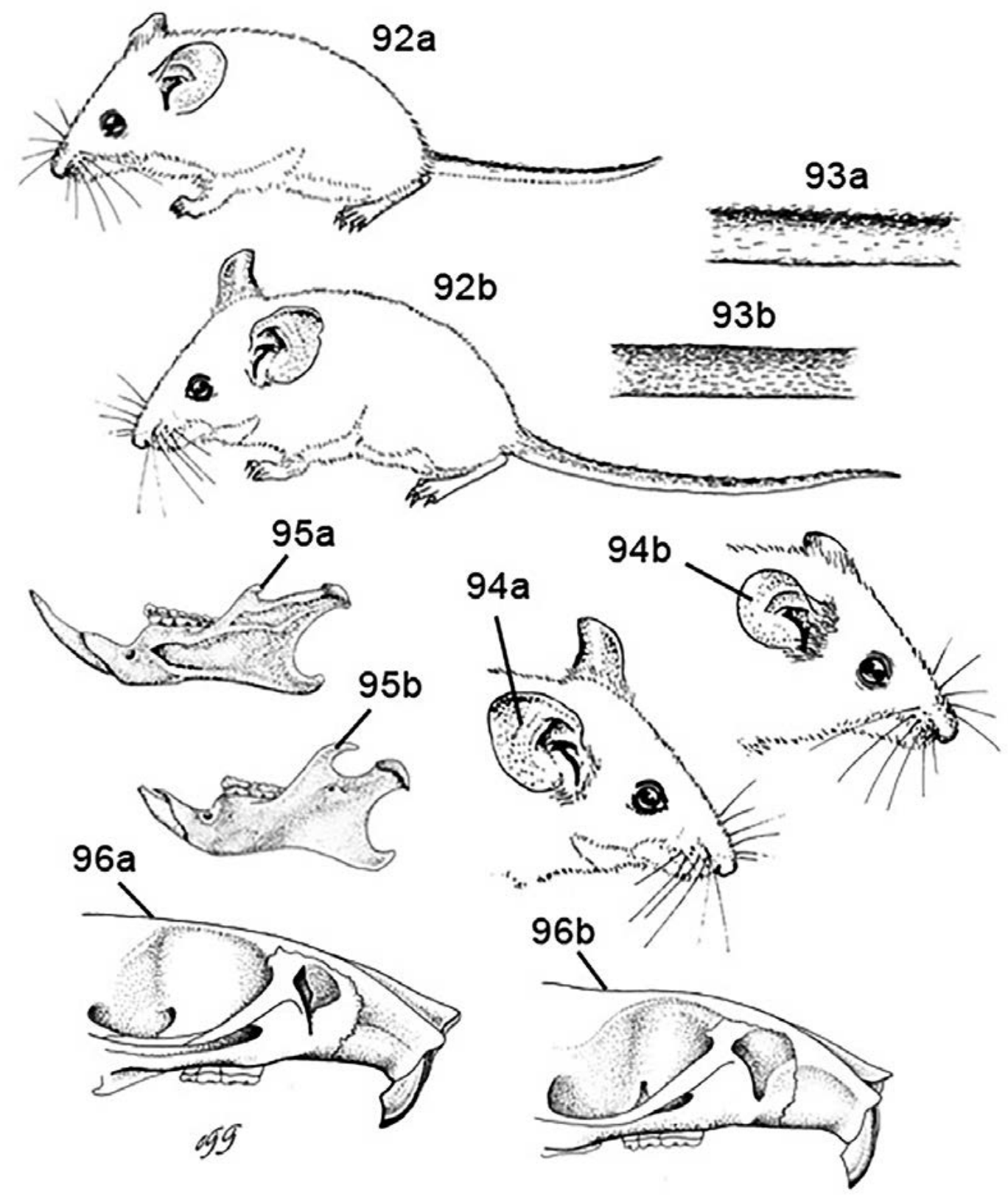

30. Orejas, anillo ocular y la base de las vibrisas negruzcas; la franja oscura sobre el dorso del cuerpo está bien definida; por lo común presentan un mechón conspicuo de pelos negros sobre la base anterior de la oreja; cráneo con el rostro relativamente largo y angosto (Fig. 100a); la longitud de los nasales es mayor de $11 \mathrm{~mm}$; muesca sobre el borde dorsal del foramen infraorbital poco prominente (Fig. 100c); la caja craneana es comparativamente ancha y redondeada (Fig. 100e). En Jalisco su distribución se restringe en la sima de la Sierra VolcánNevado de Colima, principalmente en altitudes mayores a los 2,700 m. 
30. Orejas, anillo orbital y la base de las vibrisas oscuras, pero no negruzcas; la franja oscura sobre el dorso del cuerpo no está bien definida; por lo común presentan un mechón de pelos suaves de color ante y blanco sobre la base anterior de la oreja; cráneo con el rostro relativamente corto y ancho (Fig. 100b); la longitud de los nasales es menor de $11 \mathrm{~mm}$; muesca sobre el borde dorsal del foramen infraorbital prominente (Fig. 100d); la caja craneana es relativamente angosta y está ligeramente alargada (Fig. 100f). En Jalisco su distribución se extiende ampliamente (excepto por la planicie costera) y se encuentran en distintos ambientes, principalmente en elevaciones menores a los 2,700 m

Peromyscus maniculatus

31. Orejas relativamente grandes, su longitud es mayor del $95 \%$ del largo de la pata trasera (Fig. 101a); las bulas auditivas están muy dilatadas (Fig. 102a). Se distribuyen exclusivamente en la parte semiárida del estado, que se ubica en Los Altos y norte de la entidad. .32

31 '. Orejas relativamente pequeñas, su longitud es menor del $95 \%$ del largo de la pata trasera (Fig. 101b); las bulas auditivas no están dilatadas (Fig. 102b). Se distribuyen en ambientes muy diversos de casi todo el territorio estatal

32. Individuos de talla mediana, su longitud total es menor de $215 \mathrm{~mm}$; el largo de la pata trasera es igual o menor de $24 \mathrm{~mm}$; longitud de la oreja generalmente menor de 23.5 mm; las bulas auditivas están grandemente dilatadas (Fig. 103a). Se distribuyen desde el centro-este hasta abarcar toda la región de Los Altos y parte del norte del estado Peromyscus gratus 32'. Individuos de gran tamaño, su longitud total generalmente es mayor de $215 \mathrm{~mm}$; longitud de la pata trasera mayor de $24 \mathrm{~mm}$; longitud de la oreja mayor de $23.5 \mathrm{~mm}$; las bulas auditivas están ligeramente dilatadas (Fig. 103b). Se distribuyen en la región Altos Norte y en la parte noreste del estado Peromyscus difficilis

33. La longitud de la pata trasera es igual o mayor de $24 \mathrm{~mm}$ : son de tamaño grande, longitud total entre 195 a $280 \mathrm{~mm}$; longitud occipitonasal mayor de $28 \mathrm{~mm} . . . .$.

33'. La longitud de la pata trasera principalmente es menor de $24 \mathrm{~mm}$; son de talla mediana, longitud total entre 170 a 235 mm; longitud occipitonasal menor de 28 $\mathrm{mm}$ 37

34. Es una especie de cola relativamente larga $(>130 \mathrm{~mm})$, su longitud es principalmente mayor del $120 \%$ del largo de la cabeza y el cuerpo; longitud total entre 240 a $280 \mathrm{~mm}$; el rostro es grisáceo, el cual contrasta claramente de la coloración del cuerpo (Fig. 104a); línea lateral del cuerpo ausente; el cráneo tiene los bordes supraorbitales surcados (Fig. 105a). Se distribuyen principalmente en la parte tropical y semiárida que se extiende desde el centro-noroeste, hasta la región de Los Altos y norte de la entidad. Peromyscus melanophrys

34 '. Es una especie de cola relativamente corta (usualmente $<130 \mathrm{~mm}$ ), su longitud 
es generalmente menor del $120 \%$ del largo de la cabeza y el cuerpo; longitud total entre 195 a $270 \mathrm{~mm}$; el rostro generalmente es igual a la coloración del cuerpo (Fig. 104b); línea lateral del cuerpo presente; el cráneo tiene los bordes supraorbitales sin surcos (Fig. 105b). Se distribuyen ampliamente y ocupan condiciones ambientales muy variadas en el occidente y sur del estado, principalmente desde el nivel del mar hasta aproximadamente los 2,900 m de altitud.

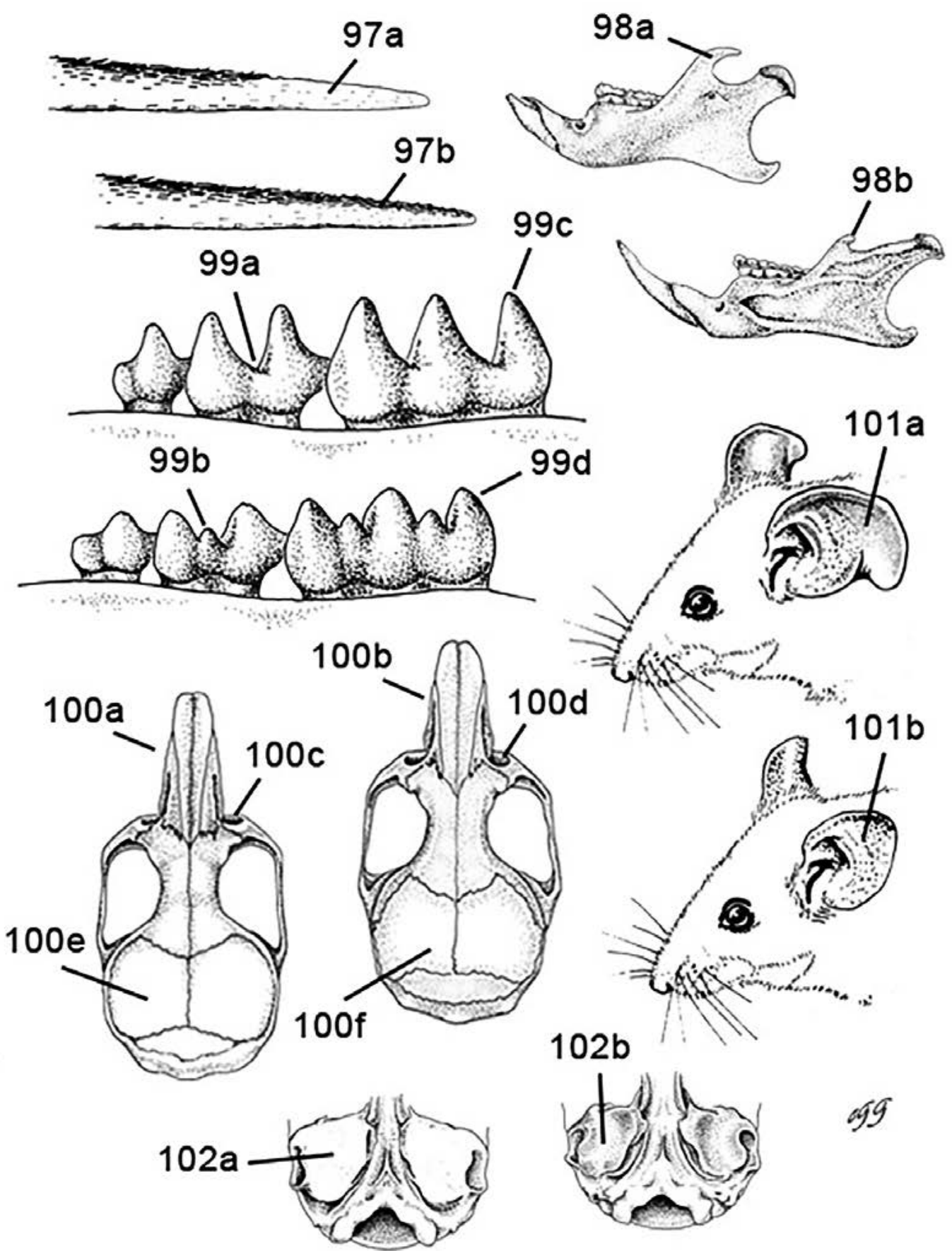


35. Color de la parte superior del cuerpo anaranjado canela brilloso, excepto por el rostro que puede ser más pálido; vientre con el pelo totalmente blanco o en ocasiones con una estrecha base gris; la cola es monocolor y está revestida escasamente de pelos cortos; la superficie dorsal de la pata trasera presenta una franja parda que se extiende hasta la base de los dedos; orejas y anillo orbital parduscos; el cráneo tiene el rostro relativamente corto y ancho (Fig. 106a). Su distribución se extiende a través de las tierras bajas ( 0 a 1,300 m de altitud) de la vertiente del Pacífico, y en el municipio de Jilotlán de los Dolores al extremo sureste del estado Peromyscus perfulvus

35'. Color de la parte superior del cuerpo ante y con el rostro igual al resto del cuerpo; vientre con la base del pelo oscura; la cola es ligera o marcadamente bicolor y está cubierta de moderada a abundantemente de pelos cortos o largos; la superficie dorsal de la pata trasera es clara, no presenta una franja pardusca; orejas y anillo orbital negruzcos; el cráneo tiene el rostro relativamente largo y angosto (Fig. 106b). Su distribución se extiende a través de las tierras bajas y montañas del occidente y sur de la entidad. .36

36. Cola relativamente larga, por lo común es mayor que la cabeza y el cuerpo; el pelaje es suave pero bastante corto, sobre todo en torno al rostro; en general el color de estos individuos es pardo amarillento pálido (ante); la cola es ligeramente bicolor y está cubierta moderadamente de pelos cortos; el cráneo presenta unas protuberancias supraorbitales notoriamente desarrolladas (Fig. 107a). Se distribuyen principalmente en la parte tropical a lo largo de la costa y zonas aledañas, y al sur y extremo sureste del estado..................................................... Osgoodomys banderanus

$36^{\prime}$. Cola relativamente corta, por lo común es igual o ligeramente menor que la cabeza y el cuerpo; el pelaje es suave pero evidentemente largo; en general el color de estos individuos varía de ante-ocráceo pálido a gris ante; la cola es marcadamente bicolor y está revestida abundantemente de pelos largos; el cráneo no presenta protuberancias supraorbitales, más bien en ocasiones los bordes de los frontales se proyectan lateralmente como ligeras repisas (Fig. 107b). Su distribución está restringida a la parte alta templada que se localiza en las Sierras Volcán-Nevado de Colima y Manantlan al sur y suroeste del estado, respectivamente. Peromyscus hylocetes

37. Tobillos blancos o al menos impregnados con un tenue pardo pálido (Fig. 108a); dorso del cuerpo de color ante-ocráceo pálido; rostro grisáceo, el cual contrasta notoriamente con la coloración del dorso del cuerpo; la anchura de la fosa mesopterigoidea es menor de $1.8 \mathrm{~mm}$; molares comparativamente pequeños, longitud de la hilera superior de dientes menor de $4.2 \mathrm{~mm}$. Se distribuyen principalmente en la región tropical y parte semiárida que se localizan desde el centro-noroeste de la entidad, extendiéndose hacia la región de Los Altos y norte del estado. Peromyscus pectoralis

37'. Tobillos más bien oscuros (Fig. 108b); dorso del cuerpo de color diferente a lo descrito anteriormente; el rostro como el resto del cuerpo; la anchura de la fosa 
mesopterigoidea es mayor de $1.8 \mathrm{~mm}$; molares comparativamente grandes, la longitud de la hilera superior de dientes normalmente es mayor de $4.2 \mathrm{~mm}$. Se distribuyen ampliamente y ocupan una gran variedad de condiciones ambientales en el estado (excepto la parte semiárida), desde el nivel del mar hasta los 2,900 m de altitud.

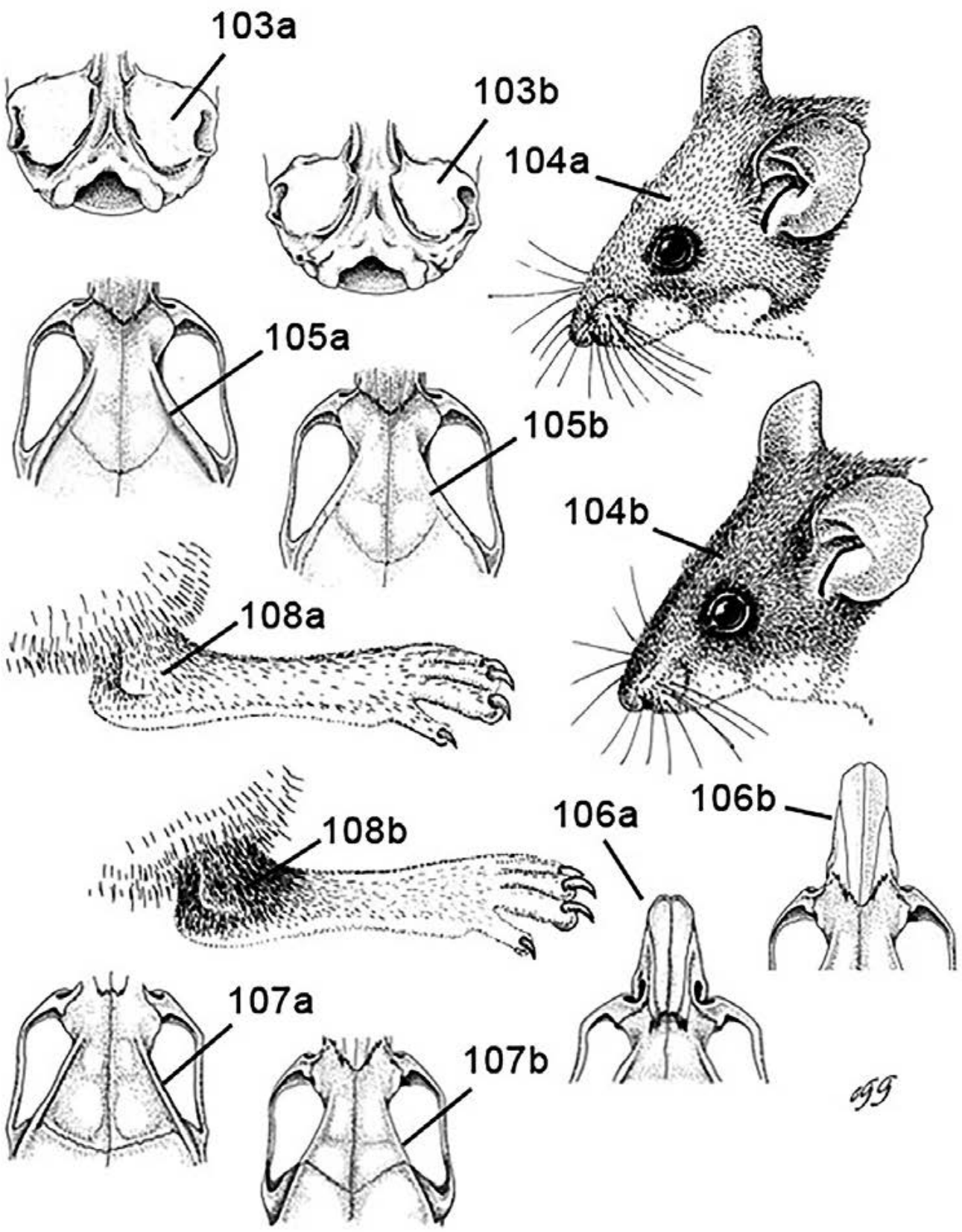

38'. Color de la parte superior del cuerpo varía de leonado brillante a un casi ocre rojizo; tienen un cuerpo relativamente robusto, el largo de la cabeza y el cuerpo por lo común es mayor de 100 mm; el cráneo tiene la región interorbital marcadamente angular (Fig. 109a). Su distribución se extiende ampliamente (excepto en la costa sur y Los Altos) y se localizan en diversas 
condiciones ambientales, desde el nivel del mar hasta los 2,200 m de altitud Peromyscus spicilegus

38. Color de la parte superior del cuerpo pardo; tienen un cuerpo relativamente esbelto, el largo de la cabeza y el cuerpo es menor de 100 mm; el cráneo tiene la región interorbital redondeada, con forma de reloj de arena (Fig. 109b). Se distribuyen principalmente en las zonas templadas que se localizan desde los $1,400 \mathrm{~m}$ hasta los 2,900 $\mathrm{m}$ de altitud.

39. Cuerpo con el dorso de color pardo madera deslustrado; la cola es indistintamente bicolor y presenta un penacho conspicuo de pelos largos sobre el ápice; orejas relativamente pequeñas, su longitud por lo común es menor de $18.5 \mathrm{~mm}$. Esta especie se distribuye probablemente en las serranías de la región de Los Altos y norte del estado Peromyscus boylii

39'. Cuerpo con el dorso de color pardo grisáceo; la cola es marcadamente bicolor y no presenta un penacho conspicuo de pelos largos sobre la porción apical; orejas evidentemente grandes, su longitud generalmente es mayor de $18.5 \mathrm{~mm}$. Esta especie se distribuye en las montañas de casi todo el territorio estatal (excepto en Los Altos) Peromyscus sp. (grupo boylii)

Clave para los géneros y especies de la familia Muridae

1. El tamaño de los individuos es pequeño, su longitud total es menor de $250 \mathrm{~mm}$; longitud de la cola menor de $110 \mathrm{~mm}$; longitud de la pata trasera menor de $24 \mathrm{~mm}$; el borde posteriordelosincisivossuperiorespresentaunamuescadistintiva, vistolateralmente (Fig. 110a). Se distribuyen prácticamente en todo el estado ...............Mus musculus

1'. Eltamañodelosindividuos esgrande, sulongitud total es mayorde $250 \mathrm{~mm}$; longitudde lacolamayorde $110 \mathrm{~mm}$; longituddelapatatraseramayorde $24 \mathrm{~mm}$; elbordeposterior de los incisivos superiores no presenta una muesca, visto lateralmente (Fig. 110b). Se distribuyen en todo el estado. Rattus 2

2. El cuerpo es esbelto y la cola relativamente larga, su longitud es mayor que la cabeza y el cuerpo; las orejas son grandes (> 20 mm) y están desnudas; cola monocolor; el cráneo presenta las crestas temporales ampliamente separadas y arqueadas externamente, de modo que la distancia entre las crestas (Fig. 111a; distancia > 13 $\mathrm{mm}$ ), es mayorquela longituddelacrestaatravésdel huesoparietal(Fig.111c); lacaja craneana es redondeada(Fig. 111e) Rattus rattus

2 '. Elcuerpoes robustoylacolarelativamentecorta, sulongitud porlocomúnesmenorque la cabeza y el cuerpo; las orejas son pequeñas $(<20 \mathrm{~mm})$ y están cubiertas con pelos cortos y finos; cola ligeramente bicolor; el cráneo presenta las crestas temporales estrechamente juntas y paralelas en relación al eje longitudinal del cráneo, de manera que la distancia entre las crestas (Fig. 111b; distancia $<13 \mathrm{~mm}$ ) es menor que la longitud de la cresta a través del hueso parietal (Fig. 111d); la caja craneana es alargada (Fig. 111f) Rattus norvegicus 

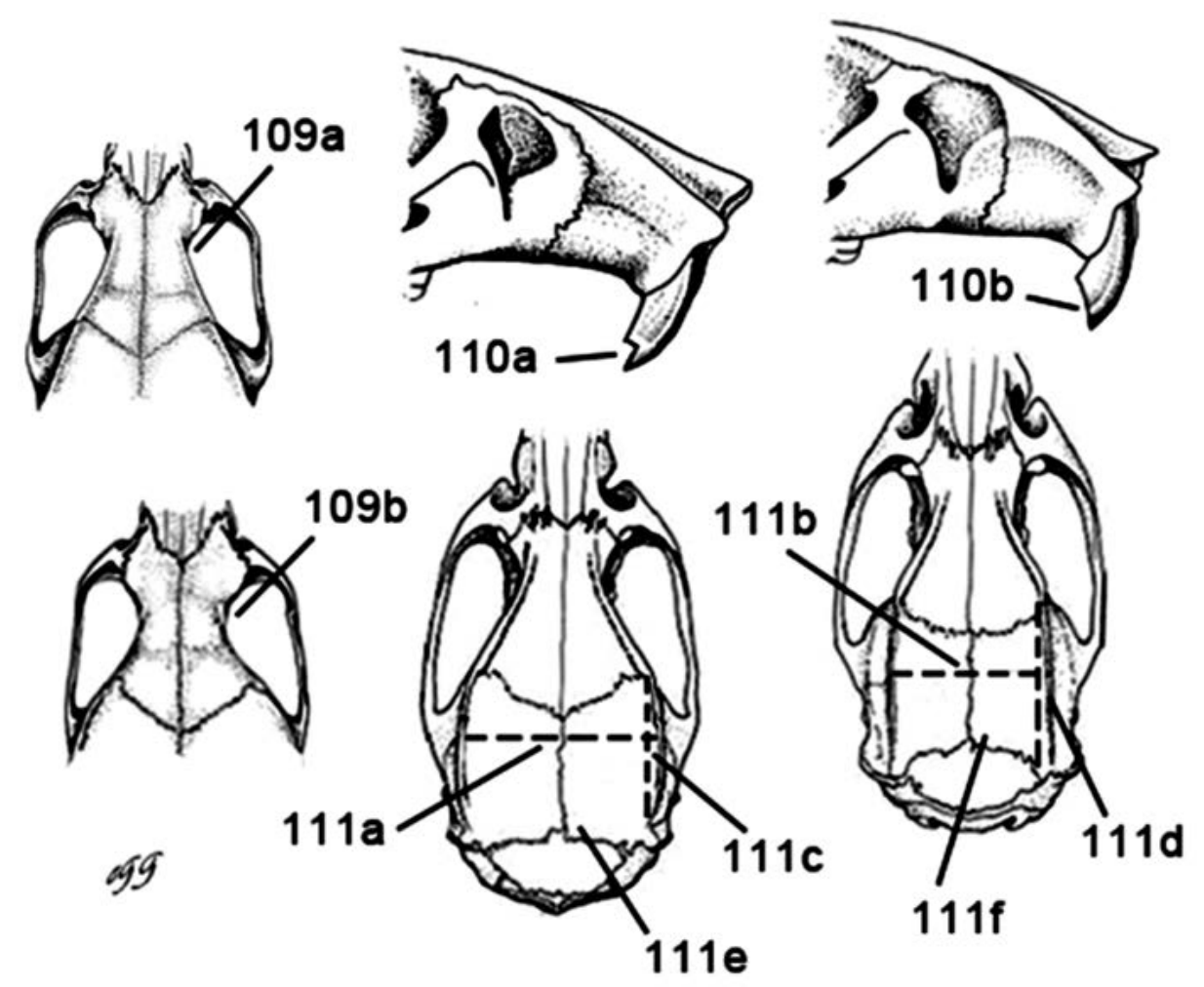

\section{Agradecimientos}

Agradecemos a S. T. Álvarez Castañeda, editor deTherya por sus sugerencias. Extendemos nuestro agradecimiento a C. Lorenzo y dos revisores anónimos por las observaciones y valiosos comentarios que ayudaron en gran medida a mejorar la calidad de este trabajo.

\section{Literatura citada}

Aluen, J. A. 1897. Further notes on mammals collected in Mexico by Dr. Audley C. Buller, with descriptions of new species. Bulletin American Museum National History 9:47-58.

Alten, J. A. 1889. Notes on a collection of mammals from southern Mexico, with descriptions of new species of the genera Sciurus, Tamias and Sigmodon. Bulletin American Museum National History 2:16518.

Auten, J. A. 1890. Notes on collections of mammals made in central and southern México, by Dr. Audley C. Buller, with descriptions of new species of the genera Vespertilio, Sciurus, and Lepus. Bulletin of the American Museum of Natural History 3:175-194.

Auten, J. A. 1906. Mammals from the states of Sinaloa and Jalisco, México, collected by J. H. Batty during 1904 and 1905. Bulletin American Museum of Natural History 22:191-262.

Aıston, E. R. 1879-1882. Biologia Centrali-Americana. Mammalia (Godman, F. D., y O. Salvin, eds.). Taylor and Francis, Red Lion Court, Fleet Street, London.

Álvarez-Castañeda, S. T. 2010. Phylogenetic structure of the Thomomys bottae-umbrinus complex in North America. Molecular Phylogenetics and Evolution 54:671-679. 
Anderson, S. 1972. Mammals of Chihuahua: Taxonomy and distribution. Bulletin of the American Museum of Natural History 148:149-410.

Balley, V. 1902. Synopsis of the North American species of Sigmodon. Proceeding of the Biological Society of Washington 15:101-116.

BaKeR, R. H. 1952. Geographic range of Peromyscus melanophrys, with description of new subspecies. University of Kansas Publications, Museum of Natural History 5:251-258.

BAKeR, R. H. 1954. The silky pocket mouse (Perognathus flavus) of Mexico. University of Kansas Publications, Museum of Natural History 7:339-347.

BaKer, R. H. 1969. Cotton rats of the Sigmodon fulviventer group (Rodentia:Muridae). Pp. 177-232 in Contributions in Mammalogy (Jones, J. K. Jr., ed.). Miscellaneous Publication, Museum of Natural History, University of Kansas. Lawrence, EE.UU.

Briones-Salas, M., y V. Sánchez-Cordero. 2004. Mamíferos. Pp. 423-447 in Biodiversidad de Oaxaca (García, A. J., M. J. Ordóñez, y M. Briones, eds.). Instituto de Biología, Universidad Nacional Autónoma de México-Fondo Oaxaqueño para la Conservación de la Naturaleza-World Wildlife Fund. Oaxaca, México.

Carleton, M. D. 1977. Interrelations of populations of Peromyscus boylii species group (Rodentia: Muridae) in western Mexico. Occasional Papers of the Museum of Zoology, University Michigan 675:1-47.

Carleton, M. D., y J. Arroyo-Cabrales. 2009. Review of the Oryzomys couesi complex (Rodentia: Cricetidae: Sigmodontinae) in western Mexico. Bulletin of the American Museum of Natural History 331:93-127.

Carleton, M. D., y G. G. Musser. 2005. Rodentia. Pp. 745-2142 in Mammal Species of the World: A taxonomic and geographic reference (Wilson, D. E., y D. M. Reeder, eds.). The Johns Hopkins University Press. Baltimore, EE.UU.

Ceballos, G., y A. Miranda. 1986. Los Mamíferos de Chamela, Jalisco: manual de campo. Instituto de Biología, Universidad Nacional Autónoma de México. Distrito Federal, México.

Ceballos, G., y A. Miranda. 2000. Guía de campo de los mamíferos de la costa de Jalisco, México. Fundación Ecológica de Cuixmala, A. C. y Universidad Nacional Autónoma de México, Instituto de Ecología/Instituto de Biología. Distrito Federal, México.

Ceballos, G., y G. Oliva (eds.). 2005. Los mamíferos silvestres de México. Fondo de Cultura Económica y Comisión Nacional para el Conocimiento y Uso de la Biodiversidad. Ciudad de México, México.

Demastes, J. W., A. L. Butt, M. S. Hafner, y J. E. Light. 2003. Systematics of a rare species of pocket gopher, Pappogeomys alcorni. Journal of Mammalogy 84:753-761.

Domínguez-Castellanos, y., F. L. Pimentel, y G. Ceballos. 2007. Uso de hábitat de roedores arborícolas en la selva seca de la Reserva de la Biósfera Chamela-Cuixmala, Jalisco. Revista Mexicana de Mastozoología 11:21-40.

Dugès, A. 1870. Catálogo de animales vertebrados observados en la República Mexicana. La Naturaleza, Serie 1 1:137-145.

Eıııo, D. G. 1903. A list of a collection of Mexican mammals with descriptions of some apparently new forms. Field Columbian Museum, Publication Zoological Series 38:141-149. 
Fernández, J. A., F. A, Cervantes, y M. S. Hafner. 2012. Molecular systematics and biogeography of the Mexican endemic kangaroo rat, Dipodomys phillipsii (Rodentia: Heteromyidae). Journal of Mammalogy 93:560-571.

Frey, J. K. 2007. Key to the rodents of New Mexico. Conservation Services Division, Department of Game and Fish, One Wildlife Way. New Mexico, EE.UU.

Genowars, H. H. 1971. A new species of spiny pocket mouse (genus Liomys) from Jalisco, Mexico. Occasional Papers of the Museum of Natural History, University of Kansas 5:1-7.

Genoways, H. H., y J. K. Jones JR. 1968. A new mouse of the genus Nelsonia from southern Jalisco, Mexico. Proceedings of the Biological Society of Washington 81:97-100.

Genoways, H. H., Y J. K. Jones JR. 1969. Notes on pocket gophers from Jalisco, Mexico, with descriptions of two subspecies. Journal of Mammalogy 50:748-755.

Genoways, H. H., Y J. K. Jones JR. 1971. Systematics of southern banner-tailed kangaroo rats of the Dipodomys phillipsii group. Journal of Mammalogy 52:265-287.

Genoways, H. H., Y J. K. Jones JR. 1973. Notes on some mammals from Jalisco, Mexico. Occasional Papers Museum, Texas Tech University 9:1-22.

Godinez, E. G., N. González-Ruiz, y J. Ramírez-Pulido. 2011. Lista actualizada de los mamíferos de Jalisco, México: Implicaciones de los cambios taxonómicos. Therya 2:7-35.

Goldman, E. A. 1905. Twelve new wood rats of the genus Neotoma. Proceedings of the Biological Society of Washington 18:27-34.

Goldman, E. A. 1910. Revision of the wood rats of the genus Neotoma. North American Fauna 31:1-124.

Goldman, E. A. 1911. Revision of the spiny pocket mice (genera Heteromys and Liomys). North American Fauna 34:1-70.

Goldman, E. A. 1918. The rice rats of North America (genus Oryzomys). North American Fauna 43:1-98.

Goldman, E. A. 1939. Review of the Pocket gophers of the genus Platygeomys. Journal of Mammalogy 20:87-93.

Guerrero, S., J. Téllez, y R. A. Salido. 1995. Los mamíferos de Jalisco: análisis zoogeográfico. BIOTAM 6:13-30.

Guerrero, S., y F. A. Cervantes. 2003. Lista comentada de los mamíferos terrestres del estado de Jalisco, México. Acta Zoológica Mexicana (n. s.) 89:93-110.

Hafner, M. S., T. A. Spradisng, J. E. Light, D. S. Hafner, y J. R. Demboski. 2004. Systematic revision of pocket gophers of the Cratogeomys gymnurus species group. Journal of Mammalogy 85:1170-1183.

Hafner, J. C., J. E. Light, D. J. Hafner, M. S. Hafner, E. Redington, D. S. Rogers, y B. R. RidDle. 2007. Basal clades and molecular systematic of heteromyid rodents. Journal of Mammalogy 88:1129-1145.

Hall, E. R., y K. R. Kelson. 1959. The mammals of North America. The Ronald Press Co., New York, EE.UU.

HALL, E. R. 1981. The mammals of North America. John Wiley and Sons, New York, EE.UU. 
Hall, E. R., y H. H. Genoways. 1970. Taxonomy of the Neotoma albigula-group of woodrats in central México. Journal of Mammalogy 51:504-516.

Hanson, J. D., J. L. Indorf, V. J. Swier, y R. D. Bradley. 2010. Molecular divergence within the Oryzomys palustris complex: evidence for multiple species. Journal of Mammalogy 91:336-347.

Helgen, K. M., F. R. Cole, L. E. Helgen, y D. E. Wilson. 2009. Generic revision in the Holarctic squirrel genus Spermophilus. Journal of Mammalogy 90:270-305.

Hooper, E. T. 1952. A systematic review of the harvest mice (genus Reithrodontomys) of Latin America. Miscellaneous Publications, Museum of Zoology, University of Michigan 77:1-255.

Hooper, E. T. 1954. A synopsis of the cricetine rodent genus Nelsonia. Occasional Papers of the Museum of Zoology, University of Michigan 558:1-12.

Hooper, E. T. 1955. Notes on mammals of western Mexico. Occasional Papers Museum Zoology, University of Michigan 565:1-26.

Howel, A. H. 1914. Revision of the American harvest mice (genus Reithrodontomys). North American Fauna 36:1-97.

Howell, A. H. 1938. Revision of the North American ground squirrels: with a classification of the North American Sciuridae. North American Fauna 56:1-256.

Iñiguez, L. I., Y E. Santana. 1993. Patrones de distribución y riqueza de especies de los mamíferos del occidente de México. Pp. 65-86 in Avances en el Estudio de los Mamíferos de México (Medellín, R. A., y G. Ceballos, eds.). Asociación Mexicana de Mastozoología, A. C. Ciudad de México, México.

IÑıguez, L. I., y E. Santana. 2005. Análisis mastofaunístico del estado de Jalisco. Pp. 253268 in Contribuciones Mastozoológicas en Homenaje a Bernardo Villa (SánchezCordero, V., y R. A. Medellín, eds.). Instituto de Biología, Instituto de Ecología y Comisión Nacional para el Conocimiento y Uso de la Biodiversidad. Ciudad de México, México.

Jones, JR., J. K., Y R. W. Manning. 1992. Illustrated key to skulls of genera of North American land mammals. Texas Tech University Press. Lubbock, Texas.

López-Forment, W., C. Sánchez, y B. Villa. 1971. Algunos mamíferos de la región de Chamela, Jalisco, México. Anales del Instituto de Biología, Universidad Nacional Autónoma de México, Serie Zoología 42:99-106.

Mandujano, S. 1997. Densidad poblacional de la ardilla gris del Pacífico (Sciurus colliaei) en un bosque tropical caducifolio de Jalisco. Revista Mexicana de Mastozoología 2:90-96.

Mathis, V. L., M. S. Hafner, D. J. Hafner, y J. W. Demastes. 2013. Thomomys nayarensis, a new species of pocket gopher from the Sierra del Nayar, Nayarit, Mexico. Journal of Mammalogy 94:983-994.

MaYr, E. 1969. Principles of Systematic Zoology, McGraw-Hill. New York, EE.UU.

Merriam, C. H. 1892. Descriptions of nine new mammals collected by E. W. Nelson in the states of Colima and Jalisco, Mexico. Proceedings of the Biological Society of Washington 7:164-174.

Merriam, C. H. 1895. Revision of the pocket gophers family Geomyidae: exclusive of the species of Thommomys. North American Fauna 8:1-259. 
Merriam, C. H. 1897. Nelsonia neotomodon, a new genus and species of murine rodent from México. Proceedings of the Biological Society of Washington 9:277-279.

Merriam, C. H. 1901a. Synopsis of the rice rats (Genus Oryzomys) of the United States and México. Proceedings of the Washington Academy of Sciences 3:273-295.

Merriam, C. H. 1901b. Descriptions of 23 new harvest mice (Genus Reithrodontomys). Proceedings of the Washington Academy of Sciences 3:547-558.

Merriam, C. H. 1902. Twenty new pocket mice (Heteromys and Liomys) from Mexico. Proceedings of the Biological Society of Washington 15:41-50.

MetCalf, Z. P. 1954. The Construction of Keys. Systematic Zoology 3:38-45.

Morales, J. C., y M. D. Engstrom. 1989. Morphological variation in the painted spiny pocket mouse, Liomys pictus (Family Heteromyidae), from Colima and southern Jalisco, México. Royal Ontario Museum, Life Sciences Contributions 38:1-16.

Musser, G. G. 1968. A systematic study of the Mexican and Guatemalan gray squirrel, Sciurus aureogaster F. Cuvier (Rodentia: Sciuridae). Miscellaneous Publications Museum of Zoology, University of Michigan 137:1-112.

Musser, G. G. 1969. Notes on Peromyscus (Muridae) of Mexico and Central America. American Museum Novitates 2357:1-23

Netson, E. W. 1899. Revision of the squirrels of México and Central America. Proceedings of the Washington Academy of Sciences 1:15-110.

Nelson, E. W., y E. A. Goldman. 1930. The pocket gophers of the genus Orthogeomys. Journal of Mammalogy 11:155-159.

Nelson, E. W., y E. A. Goldman. 1934. The pocket gophers of the genus Thomomys of mexican mainland and bordering territory. Journal of Mammalogy 15:105-124.

Osgood, W. H. 1900. Revision of the pocket mice of the genus Perognathus. North American Fauna 18:1-73.

Osgood, W. H. 1904. Thirty new mice of the genus Peromyscus from México and Guatemala. Proceedings Biological Society Washington 17:55-77.

Oscood, W. H. 1909. Revision of the mice of the American genus Peromyscus. North American Fauna 28:1-285.

Packard, R. L. 1960. Speciation and evolution of the Pygmy Mice, genus Baiomys. University of Kansas Publications, Museum of Natural History 9:579-670.

Patton, J. L., D. G. Huckaby, y S. T. Álvarez-Castañeda. 2008. The evolutionary history and a systematics revision of woodrats of the Neotoma lepida-group. University of California Publications in Zoology 135:1-411.

Ramírez-Pulido, J., J. Arroyo-Cabrales, y A. Castro-Campillo. 2005. Estado actual y relación nomenclatural de los mamíferos terrestres de México. Acta Zoológica Mexicana (n. s.) 21:21-82.

Retana, O. G. y C. Lorenzo. 2002. Lista de los mamíferos terrestres de Chiapas: endemismo y estado de conservación. Acta Zoológica Mexicana (n. s.) 85:25-49.

Roberts, H. R., K. T. Wilkins, J. Flores, y A. Thompson-Gorozpe. 1997. Burrowing ecology of pocket gophers (Rodentia: Geomyidae) in Jalisco, Mexico. The Southwestern Naturalist 42:323-327.

RusselL, R. J. 1953. Four new pocket gophers of the genus Cratogeomys from Jalisco, Mexico. University of Kansas Publications, Museum of Natural History 5:535-542. 
RusselL, R. J. 1957. A new species of pocket gopher (Genus Pappogeomys) from Jalisco, Mexico. University of Kansas Publications, Museum of Natural History 9:357-361.

RusselL, R. J. 1968. Revision of pocket gophers of the genus Pappogeomys. University of Kansas Publications, Museum of Natural History 16:581-776.

Sánchez-Cordero, V., y B. Villa-Ramírez. 1988. Variación morfométrica en Peromyscus spicilegus (Rodentia: Cricetidae) en la parte noreste de Jalisco, México. Anales del Instituto de Biología, Universidad Nacional Autónoma de México, Serie Zoología 58:819-836.

Secretaría de Medio Ambiente y Recursos Naturales (SEMARNAT). 2002. Norma Oficial Mexicana NOM-059-ECOL-2000. Protección ambiental, especies de flora y fauna silvestres de México, categorías de riesgo y especificaciones para su inclusión, exclusión o cambio, y lista de especies en riesgo. Diario Oficial de la Federación, Lunes 16 de octubre de 2001, 1:1-62.

Thomas, O. 1892. Diagnosis of a new Mexican Geomys. Annals and Magazine of Natural History, series 6 10:196-197.

Thomas, O. 1893a. Description of two new pocket mice of the genus Heteromys. Annals and Magazine of Natural History, series 6 11:329-332.

Thomas, O. 1893b. Notes on some Mexican Oryzomys. Annals and Magazine of Natural History, series 6 11:402-405.

Thomas, O. 1893c. On two new Members of the genus Heteromys and two of Neotoma. Annals and Magazine of Natural History, series 6, 12:233-235.

Vázquez, L. B., R. A Medellín, y G. N. Cameron. 2000. Population and community ecology of small rodents in Montane Forest of western México. Journal of Mammalogy 81:77-85.

Vázquez-Domínguez, E., G. Céballos, y D. Piñero. 2002. Exploring the relation between genetic structure and habitat heterogeneity in the rodent Liomys pictus from Chamela, Jalisco. Acta Zoológica Mexicana (n. s.) 86:17-28.

Villa-Ramírez, B. y F. A. Cervantes. 2003. Los mamíferos de México. Grupo Editorial Iberoamérica, S. A. de C. V. y Universidad Nacional Autónoma de México. Distrito Federal, México.

Williams, D. F., H. H. Genoways, y J. K. Braun. 1993. Taxonomy. Pp. 38-196 in Biology of the Heteromyidae (Genoways, H. H. y J. H. Brown, eds.). Special publications No. 10, American Society of Mammalogists. Lawrence, EE.UU.

Zalapa, S. S., M. H. Badi, F. A. Cervantes, y S. Guerrero. 2005. Ecología poblacional de Liomys pictus en tres áreas de bosque tropical subcaducifolio con diferente tiempo de regeneración, en la costa norte de Jalisco, México. Acta Zoológica Mexicana (n. s.) 21:1-14.

Sometido: 12 de julio de 2014

Revisado: 22 de julio de 2014

Aceptado: 7 de agosto de 2014

Editor asociado: Consuelo Lorenzo

Diseño gráfico editorial: Gerardo Hernández 